Article

\title{
Structural Performance of Polymer Fiber Reinforced Engineered Cementitious Composites Subjected to Static and Fatigue Flexural Loading
}

\author{
Mohamed A.A. Sherir, Khandaker M.A. Hossain * and Mohamed Lachemi \\ Department of Civil Engineering, Ryerson University, 350 Victoria Street, Toronto, ON M5B 2K3, \\ Canada; E-Mails: msherir@ryerson.ca (M.A.A.S.); mlachemi@ryerson.ca (M.L.) \\ * Author to whom correspondence should be addressed; E-Mail: ahossain@ryerson.ca; \\ Tel.: +1-416-979-5000 (ext. 7867).
}

Academic Editor: Alexander Böker

Received: 22 April 2015 / Accepted: 2 July 2015 / Published: 14 July 2015

\begin{abstract}
This paper presents the influence of silica sand, local crushed sand and different supplementary cementing materials (SCMs) to Portland cement $(\mathrm{C})$ ratio $(\mathrm{SCM} / \mathrm{C})$ on the flexural fatigue performance of engineered cementitious composites (ECCs). ECC is a micromechanically-based designed high-performance polymer fiber reinforced concrete with high ductility which exhibits strain-hardening and micro-cracking behavior in tension and flexure. The relative high cost remains an obstacle for wider commercial use of ECC. The replacement of cement by SCMs, and the use of local sand aggregates can lower cost and enhance greenness of the ECC. The main variables of this study were: type and size of aggregates (local crushed or standard silica sand), type of SCMs (fly ash "FA" or slag), $\mathrm{SCM} /$ cement ratio of 1.2 or 2.2 , three fatigue stress levels and number of fatigue cycles up to 1 million. The study showed that ECC mixtures produced with crushed sand (with high volume of fly ash and slag) exhibited strain hardening behavior (under static loading) with deformation capacities comparable with those made with silica sand. Class F-fly ash combined with crushed sand was the best choice (compared to class CI fly ash and slag) in order to enhance the ECC ductility with slag-ECC mixtures producing lowest deflection capacity. FA-ECC mixtures with silica sand developed more damage under fatigue loading due to higher deflection evolution than FA-ECC mixtures with crushed sand.
\end{abstract}


Keywords: engineered cementitious composite; supplimentary cementing materials; polyvinyl alcohol fiber; fatigue flexure; strain hardening; micro-cracking

\section{Introduction}

For decades, normal cementitious materials have proven to be a suitable material in infrastructure constructions and have been successfully implemented in numerous projects around the world. However, the deteriorating condition of the infrastructure in North America and elsewhere due to inherently brittle failure resulting from tensile and impact loading in such cementitious materials has motivated authorities and researchers to seek new technology for enhancement of concrete material properties. Therefore, polymeric fibers were employed as a reinforcing material in cementitious materials in order to enhance the resistance and toughness in tension and shear. Four thousand years ago, fiber reinforcement in construction materials started to be used in the Far East regions when horsehair or hays were mixed into the mud for bricks for housing construction. Modern fiber reinforced cementitious materials have been studied since 1960s [1].

In the last decade, a new type of composite called Engineered Cementitious Composite (ECC) has been developed. ECC is a special type of high performance fiber-reinforced cementitious composite featuring high ductility and damage tolerance under mechanical loading, including tensile and shear loadings [2-4]. By employing micromechanics-based material optimization, tensile strain capacity in excess of $3 \%$ under uniaxial tensile loading can be attained with only $2 \%$ polyvinyl alcohol (PVA) fiber content by volume $[2,5,6]$. Unlike most vinyl polymers, PVA is not prepared by polymerization of the corresponding monomer. The monomer, vinyl alcohol, is unstable with respect to acetaldehyde. PVA instead is prepared by first polymerizing vinyl acetate, and the resulting polyvinylacetate is converted to the PVA.

The characteristic ECC strain hardening after matrix first cracking is accompanied by sequential development of multiple micro-cracking and the tensile strain capacity is 300-500 times greater than that of normal concrete. The formation of multiple micro cracking is necessary to achieve high composite tensile ductility. Even at ultimate load, the crack width remains on the order of 50 to 80 micrometer. This tight crack width is self-controlled and, whether the composite is used in combination with conventional reinforcement or not, it is a material characteristic independent of rebar reinforcement ratio.

In contrast, normal concrete and fiber reinforced concrete (FRC) rely on steel reinforcement for crack width control. By suppressing cracks in the presence of large imposed structural deformations, ECC can offer structural durability improvements in addition to water-tightness and other serviceability enhancements. These properties, together with a relative ease of production including self-consolidation casting [7,8] and shotcreting [9], make ECCs suitable for various civil engineering applications. Currently, self-consolidating ECC is emerging in full scale structural applications [10]. The ingredients and mix proportions of ECC are optimized through micromechanics based material design theory to satisfy strength and energy criteria to attain high composite tensile ductility [2-4,11]. The type, size and amount of fiber, matrix ingredients and interface characteristics are tailored for multiple cracking and controlled crack width in ECCs. 
Aggregates typically occupy an important volume fraction in conventional concrete, and therefore have important effects on different aspects of material properties. In addition to their role as economic filler, aggregates help to control dimensional stability of cement-based materials, which may be considered to consist of a framework of cement paste with relatively large shrinkage movements restrained by aggregates. However, the presence of coarse aggregates in a paste tends to increase the tortuosity of the fracture path, and lead to a tough matrix which delays crack initiation and prevents steady-state flat-crack propagation in ECC, resulting in loss of tensile ductility. Moreover, the introduction of aggregates with a particle size larger than the average fiber spacing leads to balling and greater interaction of fibers between the large aggregate particles, and the effect becomes more pronounced as the maximum size of aggregate particles increase. Therefore, an increase in aggregate size makes it more difficult to achieve a uniform dispersion of fibers. The greater the size of aggregates, the more clumping and interaction of fibers would occur. Therefore, the size of the aggregates is expected to have a significant influence on the properties of composite. Hence, in spite of positive effects of aggregates on dimensional stability and economy of fiber reinforced cement composites, there are limits on aggregate size beyond which problems with fiber dispersability, fresh mix workability and matrix toughness may start to damage the composite material performance characteristics [12].

Therefore, instead of coarse aggregate, standard ECC incorporates fine aggregate (generally silica sand) with an aggregate to binder ratio (A/B) of 0.36 by mass to maintain adequate stiffness and volume stability [13]. The binder system is defined as the total amount of cementitious material, i.e., cement and SCMs, generally fly ash (FA), in ECC. The silica sand has a maximum grain size of $250 \mu \mathrm{m}$ and a mean size of $110 \mu \mathrm{m}$. Another purpose of using fine silica sand is to obtain the optimum gradation of particles to produce good workability [14].

Due to environmental and economic reasons, there is a growing trend to use industrial wastes or by-products as supplementary materials or admixtures in the production of cementitious composite. Among the various supplementary materials, fly ash (FA) and slag (SL) are the most commonly available SCMs. Because of several potential benefits, fly ash and slag have increasingly found use in high performance concrete in the last few decades [15].

In the past few decades, substitution of SCMs, such as FA and SL, has been of great interest and gradually applied to practical applications of ECC [16-20]. FA is a by-product of the coal power plant, whereas SL is a by-product in the manufacture of pig iron. Both of these waste materials from industrial processes are usually available in large quantities and at a fraction of the price of cement. The absence of coarse aggregate in ECC results in a higher cement content. Partial replacement using FA or SL reduces the environmental burden. Further, it has been found that incorporating high amount of FA, especially class F fly ash, can reduce the matrix toughness and improve the robustness of ECC in terms of tensile ductility. Additionally, un-hydrated FA particles with small particle size and smooth spherical shape serve as filler particles resulting in higher compactness of the fiber/matrix interface transition zone that leads to a higher frictional bonding. This aids in reducing the steady-state crack width beneficial for long-term durability of the structure [18,19,21,22]. The leaking expansion joints are a major source of deterioration of multi-span bridges in Canada. Expansion joints can be replaced by flexible link slabs made with ECC forming a joint-free multi-span bridge and hence, solving the problem of premature deterioration [23,24]. Research studies showed significant enhancement of ductility and crack width 
control in ECC link slabs confirming that the use of ECC can be effective in extending the service life of bridge deck systems.

Since the increase in aggregate size leads to an increase in the matrix toughness while the use of SCMs leads to reduce the matrix toughness, locally available aggregate could successfully be used in conjunction with high volume SCMs in the production of ECC. Very limited information is currently available in the published literature revealing the influence of aggregate size on the performance (ductility and mechanical behavior) of ECC [12]. Accordingly, one of the current research goals is to design a new class of ECCs with a matrix incorporating locally available aggregates that can show similar mechanical properties compared to standard ECC mixtures containing silica sand.

The main objective of the current research is to explore the development of greener ECCs and analyze the mechanical properties such as flexural strengths and fatigue loading performance of ECCs. Flexure fatigue performance of ECC is very important for its construction applications, for example, link slabs applications in bridge decks.

The present study contributes the existing knowledge of ECC by incorporating locally available crushed sand instead of silica sand and by employing different cement replacement rates up to $70 \%$. It is well known that commercially available silica sand is relatively expensive and difficult to obtain when compared with commonly available sands, such as crushed sand. This paper describes the results of an experimental investigation studying the effects of silica sand (as a control material), local crushed sand and different SCM/C ratio on the flexural properties and fatigue performance as well as crack development characteristics of ECC mixtures. Overall, the recommendations of this paper will be beneficial to engineers, designers and local industries engaged in manufacturing and using cost-effective and greener ECC mixtures for construction applications.

\section{Experimental Investigations}

Two phases of tests were carried on prismatic prism (beam) samples made of two groups of twelve ECC mixtures designed and selected for this study.

Phase I: This phase consisted of two parts. The first part was static flexural strength test conducted at 28, and 56 days for both ECC groups. The second part was general fatigue flexural test conducted at 28 days for 50,000 cycles at $4 \mathrm{~Hz}$ cyclic loading rate and 55\% fatigue flexural stress level. At the end of the fatigue flexural tests, static flexural tests were applied on the fatigued ECC specimens to calculate the fatigue residual energy. The best ECC mixtures identified from this phase were included in the second phase (Phase II) - slag mixtures were omitted at the end of this phase because of their inferior multiple cracking behavior.

Phase II: In this phase, special fatigue flexure tests were conducted by using two different approaches. The first approach was applying different fatigue flexural stress levels namely $40 \%, 55 \%$ and $70 \%$ of the average maximum stress for 50,000 cycles at $4 \mathrm{~Hz}$ cyclic loading rate and the second approach was applying different fatigue cycles namely 200,000, 300,000 and 1,000,000 cycles at $4 \mathrm{~Hz}$ cyclic loading rate and $55 \%$ fatigue stress level. 


\subsection{Materials and ECC Mixture Proportions}

The material used in the production of standard ECC mixtures were Portland cement (C) Type I general use (GU); two different classes of fly ash (FA): Class-F, and Class-CI with calcium content $5.57 \%$, and $14.30 \%$ respectively; Blast furnace slag (SL) with calcium content of $40.80 \%$; silica sand (SS) with a maximum grain size of $0.40 \mathrm{~mm}$; polyvinyl alcohol (PVA) fibers; water; and a polycarboxylic-ether type high-range water-reducing admixture (HRWRA). The chemical composition and physical properties of Portland cement, class-F; class-CI fly ash and slag are presented in Table 1. The commercially available silica sand is relatively expensive and difficult to obtain when compared with commonly available sands [12]. For this purpose, locally available crushed lime stone sand with maximum grain size of $1.18 \mathrm{~mm}$ was used in the production of nonstandard ECC mixtures. The grain size distributions of silica sand and crushed sand are given in Table 2. The PVA fibers with a diameter of $39 \mu \mathrm{m}$ and a length of $8 \mathrm{~mm}$ are purposely manufactured with a tensile strength (1620 MPa), elastic modulus (42.8 GPa), and maximum elongation (6.0\%) matching those needed for strain-hardening performance. Additionally, the surface of the PVA fibers was coated with a proprietary oiling agent $1.2 \%$ by mass to tailor the interfacial properties between fiber and matrix for strain-hardening performance [25].

Table 1. Chemical properties of Portland cement, fly ashes and slag.

\begin{tabular}{ccccc}
\hline Chemical Composition (\%) & Cement (C) & Fly Ash (F) & Fly Ash (CI) & Slag (SL) \\
\hline Calcium Oxide $\mathrm{CaO}$ & 61.40 & 5.57 & 14.30 & 40.8 \\
Silicon Dioxide $\mathrm{SiO}_{2}$ & 19.60 & 59.5 & 41.57 & 35.4 \\
Aluminium Oxide $\mathrm{Al}_{2} \mathrm{O}_{3}$ & 4.90 & 22.2 & 26.12 & 13.00 \\
Ferric Oxide $\mathrm{Fe}_{2} \mathrm{O}_{3}$ & 3.10 & 3.90 & 8.44 & 0.50 \\
Magnesium Oxide $\mathrm{MgO}$ & 3.00 & - & 3.40 & 8.00 \\
Sulfur Trioxide $\mathrm{SO}_{3}$ & 3.60 & 0.19 & 1.55 & 0.10 \\
Alkalis as $\mathrm{Na}_{2} \mathrm{O}$ & - & 2.75 & 0.71 & 0.20 \\
Loss on ignition $\mathrm{LOI}$ & 2.30 & 0.21 & 1.49 & - \\
$\mathrm{Sum}\left(\mathrm{SiO}_{2}+\mathrm{Al}_{2} \mathrm{O}_{3}+\mathrm{Fe}_{2} \mathrm{O}_{3}\right)$ & 27.60 & 85.6 & 76.13 & 48.9 \\
Physical properties & - & Fly Ash $(\mathrm{F})$ & Fly Ash $(\mathrm{CI})$ & $\mathrm{Slag}(\mathrm{SL})$ \\
Residue $45 \mu \mathrm{m}(\%)$ & 3.00 & 9.60 & 17.50 & 1.00 \\
Density $\left(\mathrm{g} / \mathrm{cm}^{3}\right)$ & 3.15 & 2.18 & 2.43 & 2.11 \\
Blaine fineness $\left(\mathrm{m}^{2} / \mathrm{kg}\right)$ & 410 & 306 & - & 430 \\
Air Content $(\%)$ & 7.79 & - & - & - \\
Initial Setting time $(\mathrm{min})$ & 113 & - & - & - \\
Compressive Strength $(\mathrm{MPa}) 1$ day & 19.41 & - & - & - \\
Compressive Strength $(\mathrm{MPa}) 3$ day & 30.35 & - & - & - \\
Compressive Strength $(\mathrm{MPa}) 28$ day & 41.47 & - & - & - \\
\hline
\end{tabular}


Table 2. Sieve analysis of silica sand and crushed sand.

\begin{tabular}{cccc}
\hline U.S. Sieve \# & Opening $(\mathbf{m m})$ & \% Retained crushed sand & \% Retained silica sand \\
\hline 16 & 1.18 & 0.00 & - \\
20 & 0.841 & 6.0 & - \\
30 & 0.60 & 17.50 & - \\
40 & 0.42 & - & 0.00 \\
50 & 0.30 & 60.0 & 2.20 \\
70 & 0.21 & - & 14.70 \\
100 & 0.15 & 90.25 & 47.50 \\
140 & 0.105 & - & 28.80 \\
200 & 0.074 & 98.75 & 6.40 \\
270 & 0.053 & - & 0.40 \\
\hline
\end{tabular}

In order to investigate the influence of aggregate type and size, and different supplementary cementing materials on the mechanical properties of ECC, two main groups of 12 ECC mixtures have been designed and selected. The first group was composed of 6 ECC mixtures which were produced using silica sand. The second group was composed of the same first group ECC mixtures but was produced using local crushed sand. The supplementary cementing materials (SCMs) used in both groups were Class-CI, Class-F fly ash and Slag. These SCMs were used as Portland cement replacement at ratios of 1.2 and $2.2(55 \%$ and $70 \%$ by mass), respectively. Mixture proportions and designations for both groups of ECC mixtures are given in Table 3.

Table 3. Engineered cementitious composites (ECC) Mixture proportions.

\begin{tabular}{|c|c|c|c|c|c|c|c|c|c|}
\hline \multicolumn{10}{|c|}{ First Group-Silica Sand } \\
\hline \multirow{2}{*}{$\begin{array}{l}\text { Mixture } \\
\text { ID }\end{array}$} & \multicolumn{7}{|c|}{ Ingredients Per 1 Part of Cement by Mass } & \multirow{2}{*}{$\begin{array}{c}\text { FA/C or } \\
\text { SL/C }\end{array}$} & \multirow{2}{*}{$\mathbf{W} / \mathbf{B}$} \\
\hline & Water & Cement & FA & Slag & Sand & PVA kg/m $\mathrm{m}^{3}$ & HRWRA kg/m ${ }^{3}$ & & \\
\hline CI_1.2_SS & 0.60 & 1 & 1.2 & - & 0.80 & 26 & 5.4 & 1.2 & 0.27 \\
\hline CI_2.2_SS & 0.85 & 1 & 2.2 & - & 1.15 & 26 & 4.2 & 2.2 & 0.27 \\
\hline F_1.2_SS & 0.60 & 1 & 1.2 & - & 0.80 & 26 & 5.4 & 1.2 & 0.27 \\
\hline F_2.2_SS & 0.85 & 1 & 2.2 & - & 1.15 & 26 & 4.2 & 2.2 & 0.27 \\
\hline $\mathrm{SL} \_1.2 \_\mathrm{SS}$ & 0.67 & 1 & - & 1.2 & 0.80 & 26 & 4.50 & 1.2 & 0.30 \\
\hline $\mathrm{SL} \_2.2 \_\mathrm{SS}$ & 0.96 & 1 & - & 2.2 & 1.15 & 26 & 3.80 & 2.2 & 0.30 \\
\hline \multicolumn{10}{|c|}{ Second Group-Crushed Sand } \\
\hline Mixture & \multicolumn{7}{|c|}{ Ingredients Per 1 Part of Cement by Mass } & \multirow{2}{*}{$\begin{array}{c}\text { FA/C or } \\
\text { SL/C }\end{array}$} & \multirow{2}{*}{$\mathbf{W} / \mathbf{B}$} \\
\hline ID & Water & Cement & FA & Slag & Sand & PVA & HRWRA & & \\
\hline CI_1.2_CS & 0.60 & 1 & 1.2 & - & 0.80 & 26 & 5.4 & 1.2 & 0.27 \\
\hline CI_2.2_CS & 0.85 & 1 & 2.2 & - & 1.15 & 26 & 4.2 & 2.2 & 0.27 \\
\hline $\mathrm{F} \_1.2 \_\mathrm{CS}$ & 0.60 & 1 & 1.2 & - & 0.80 & 26 & 5.4 & 1.2 & 0.27 \\
\hline F_2.2_CS & 0.85 & 1 & 2.2 & - & 1.15 & 26 & 4.2 & 2.2 & 0.27 \\
\hline $\mathrm{SL} \_1.2 \_\mathrm{CS}$ & 0.67 & 1 & - & 1.2 & 0.80 & 26 & 4.50 & 1.2 & 0.30 \\
\hline SL_2.2_CS & 0.96 & 1 & - & 2.2 & 1.15 & 26 & 3.80 & 2.2 & 0.30 \\
\hline
\end{tabular}

HRWRA: High range water reducing admixture; C: Cement; FA: fly ash; CI: class-CI Fly Ash; F: class-F Fly Ash; SL: Slag; W/B: water to binder ratio (binder $=\mathrm{C}+\mathrm{SCMs}$ ). 
The water/binder (W/B) ratio was kept in the range of 0.27 for both class CI and F fly ash and 0.30 for slag. The variable parameters in these mixtures were the aggregate type and size, and SCMs cement replacement rate (SCM/C of 1.2 and 2.2). In both groups, the amount of aggregate and SCMs to binder were held constant.

As shown in Table 3, the ECC mixtures are labeled such that the ingredients are identifiable from their Mix IDs. The first letter in the mixture designations indicates the SCM type (CI, class-CI fly ash; F, class-F fly ash; SL, slag). The numbers after the letter indicate the SCM (CI, F or SL) - cement ratio and last letters represent aggregate type (SS or CS).

\subsection{Specimen Preparation}

Hobart type mixer with 20-liter capacity was used in preparing all ECC mixtures. All materials of ECC mixtures were weighed separately before starting mixing. All dry materials except PVA fiber such as cement, SCMs (FA or SL), and silica or crushed sands were thrown into the mixer for the dry mix. After $30 \mathrm{~s}$ dry mix, $90 \%$ of water was added into the mixer for another $2 \mathrm{~min}$. Then the remaining 10\% of water and HRWRA were added within the next $1 \mathrm{~min}$. The final step of mixing procedure was to add the PVA fiber into the mixer and the mix was stirred for another $3 \mathrm{~min}$. It should be noted that HRWRA content was not kept constant which means slight adjustment in the amount of HRWRA in each mixture was performed to achieve better fiber dispersion and workability based on past experience.

In the fresh state, workability of ECC mixtures was determined by slump flow test according to ASTM C 1611 [26]. Cube specimens measuring $50 \mathrm{~mm} \times 50 \mathrm{~mm} \times 50 \mathrm{~mm}$ were cast to determine compressive strength at the age of 28 days. Although the scope of the paper is limited to the behavior of ECC under flexural loading, the results of slump flow and compressive strength tests are summarized in Table 4. Slump flow values of ECC mixtures ranged between 415 and $540 \mathrm{~mm}$. All ECC mixtures were found flowable and showed no bleeding. The 28 day compressive strength varied from 45 to $69 \mathrm{MPa}$. ECC mixtures with class CI fly ash exhibited slightly higher compressive strength than Class F while those with Slag showed higher compressive strength than those with fly ash CI or F-the higher compressive strength was attributed to the higher content of $\mathrm{CaO}$. The compressive strength decreases with the increase of fly ash content while decreased with the replacement of silica sand by crushed sand.

$355 \mathrm{~mm} \times 50 \mathrm{~mm} \times 76 \mathrm{~mm}$ prism (beam) specimens were prepared for the four-point bending test. The total number of all prismatic specimens prepared for this study was 168 beams. All specimens were demolded after $24 \mathrm{~h}$ and moisture cured in plastic bags at $95 \% \pm 5 \%$ relative humidity $(\mathrm{RH}), 23 \pm 2{ }^{\circ} \mathrm{C}$. The specimens were kept in the curing room until the day of testing.

\subsection{Test Procedures}

Three prismatic samples of $355 \mathrm{~mm} \times 50 \mathrm{~mm} \times 76 \mathrm{~mm}$ were prepared to measure the flexural strength of ECC (Modulus of rupture), for ages 28 and 56 days by performing four-point bending test under displacement control condition at a loading rate of $0.005 \mathrm{~mm} / \mathrm{s}$ on a closed-loop servo-controlled loading system. The span length of flexural loading was $304.8 \mathrm{~mm}$ with a $101.6 \mathrm{~mm}$ center span length. During the flexural tests, the load and the mid-span deflection were recorded on a computerized data recording system. The schematic of the test setup with a photo is presented in Figure 1. Flexural strength of the specimens was calculated in accordance with ASTM C 78 [27]. 
Table 4. Average flexural strength and ultimate deflection results at ages 28 and 56 days.

\begin{tabular}{|c|c|c|c|c|c|c|c|}
\hline \multirow{3}{*}{ Mix No. } & \multirow{3}{*}{ Mix Designation } & \multirow{3}{*}{ Slump Flow (mm) } & \multirow{3}{*}{$\begin{array}{l}\text { 28-Day Compressive } \\
\text { Strength (MPa) }\end{array}$} & \multicolumn{4}{|c|}{ Flexural Properties } \\
\hline & & & & \multicolumn{2}{|c|}{28 Days } & \multicolumn{2}{|c|}{56 Days } \\
\hline & & & & Strength (MPa) & Deflection (mm) & Strength (MPa) & Deflection (mm) \\
\hline 1 & CI_1.2_SS & 540 & $62( \pm 2)$ & $12.68( \pm 0.5)$ & $3.17( \pm 0.2)$ & $13.83( \pm 0.5)$ & $2.67( \pm 0.15)$ \\
\hline 3 & $\mathrm{~F} \_1.2 \_\mathrm{SS}$ & 535 & $61( \pm 2)$ & $11.80( \pm 0.5)$ & $3.91( \pm 0.2)$ & $12.38( \pm 0.5)$ & $3.75( \pm 0.15)$ \\
\hline 4 & F_2.2_SS & 530 & $52( \pm 2)$ & $10.84( \pm 0.5)$ & $4.45( \pm 0.2)$ & $12.25( \pm 0.5)$ & $3.98( \pm 0.15)$ \\
\hline 5 & $\mathrm{SL} \_1.2 \_\mathrm{SS}$ & 550 & $69( \pm 2)$ & $15.44( \pm 0.5)$ & $1.79( \pm 0.2)$ & $15.81( \pm 0.5)$ & $1.74( \pm 0.15)$ \\
\hline 8 & CI_2.2_CS & 500 & $47( \pm 2)$ & $11.42( \pm 0.5)$ & $3.14( \pm 0.2)$ & $12.64( \pm 0.5)$ & $2.56( \pm 0.15)$ \\
\hline 9 & F_1.2_CS & 490 & $59( \pm 2)$ & $11.20( \pm 0.5)$ & $3.66( \pm 0.2)$ & $12.12( \pm 0.5)$ & $3.26( \pm 0.15)$ \\
\hline 10 & F_2.2_CS & 515 & $45( \pm 2)$ & $10.48( \pm 0.5)$ & $4.27( \pm 0.2)$ & $11.68( \pm 0.5)$ & $4.02( \pm 0.15)$ \\
\hline 11 & $\mathrm{SL}_{-}^{-} 1 . \overline{2} \_\mathrm{CS}$ & 420 & $69( \pm 2)$ & $14.93( \pm 0.5)$ & $1.73( \pm 0.2)$ & $15.24( \pm 0.5)$ & $1.61( \pm 0.15)$ \\
\hline 12 & $\mathrm{SL} 2.2 \_\mathrm{CS}$ & 415 & $67( \pm 2)$ & $13.62( \pm 0.5)$ & $1.80( \pm 0.2)$ & $13.87( \pm 0.5)$ & $1.64( \pm 0.15)$ \\
\hline
\end{tabular}
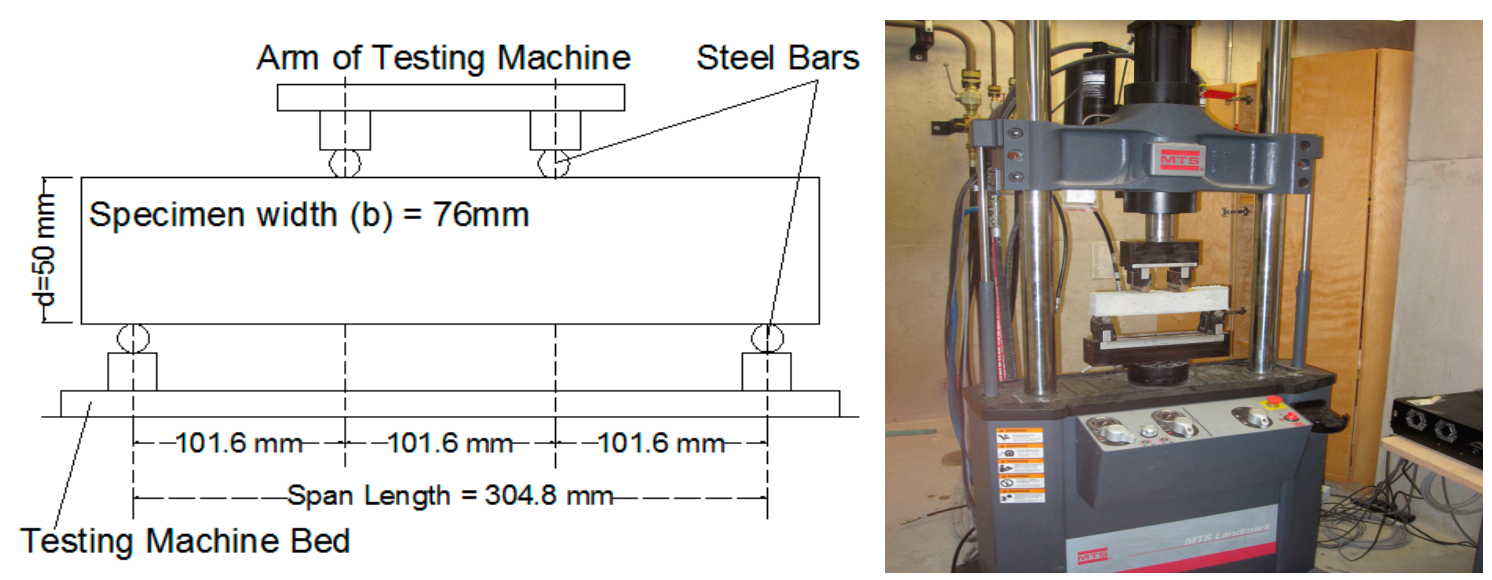

Figure 1. Four point bending test setup. 
Two approaches were adopted for investigating the ECC performance under fatigue flexural test: the first was applying different fatigue stress levels and the second was applying different fatigue cyclic loading. Accordingly, four prismatic samples of $355 \mathrm{~mm} \times 50 \mathrm{~mm} \times 76 \mathrm{~mm}$ were prepared for the age of 28 days. The four-point bending test was conducted under both static and fatigue loading. Two out of four samples were prepared for static loading tests as control specimens which were carried out under displacement control conditions, while the other two samples were prepared for fatigue loading tests which were performed under load control conditions. Specimens were simply supported on a span of $304.8 \mathrm{~mm}$ and subjected to two-point loads at one-third of the span as shown in Figure 1.

In the first approach, static flexural tests were conducted before fatigue flexural tests at the constant rate of $0.005 \mathrm{~mm} / \mathrm{s}$. The static flexural strengths were determined by averaging the flexural strength results of ECC control specimens. Based on their static flexural averages, the different maximum fatigue stress levels were determined as $40 \%, 55 \%$ and $70 \%$ and the tests were conducted at 50,000 cycles and $4 \mathrm{~Hz}$ cyclic loading rate. In the second approach, $55 \%$ of fatigue stress level value was fixed and tests were conducted at different fatigue cycles namely 200,000 cycles, 300,000 cycles and 1,000,000 cycles at the same $4 \mathrm{~Hz}$ cyclic loading rate as well.

Fatigue flexural tests were performed under load control conditions. The ratio between minimum and maximum flexural stress was set equal to 0.30 for all specimens in order to avoid any impact and slip of specimens during testing. At the first cycle of each specimen, load was gradually applied to the maximum stress level at $0.50 \mathrm{kN} / \mathrm{min}$ static loading rate in order to avoid any sudden collapse in the specimen. The cyclic fatigue loading was then applied. The fatigue testing technique mentioned above was adopted in accordance with Suthiwarapirak et al. [28]. During the fatigue flexural tests, the mid-span deflection evolutions were recorded on data sheet and at the end of the fatigue flexural tests; static flexural tests were conducted on the fatigued ECC specimens to calculate the fatigue residual values for both strength and mid-span deflection.

\section{Analysis of Behavior under Static Flexural Loading (Phase I)}

\subsection{Flexural Strength}

The test results in terms of flexural strength, modulus of rupture (MOR), and ultimate mid-span deflection are given in Table 4 at ages 28 and 56 days, and the average flexural strength-mid span deflection curves of ECC mixtures at age of 28 days are shown in Figure 2. Each result in Table 4 is the average of three measurements.

As seen from Table 4, the average ultimate flexural strengths vary from 10.48 to $15.81 \mathrm{MPa}$ and the mid-span deflection (deflection capacity) of the ECC beams vary from 1.61 to $4.45 \mathrm{~mm}$ depending on fly ash class CI, F and slag content. 

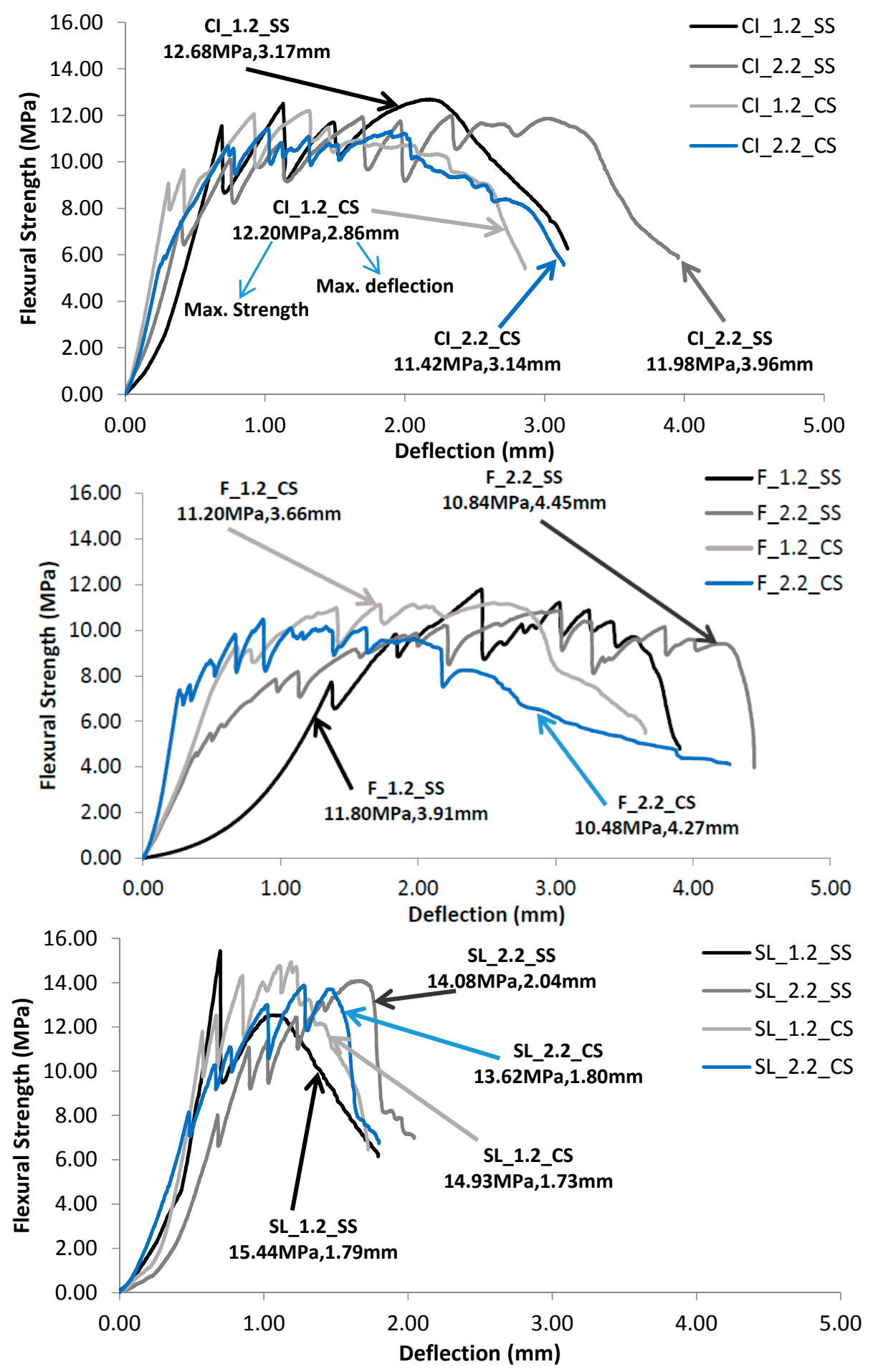

Figure 2. Average flexural strength-mid span deflection curves of ECCs at 28 days.

\subsection{ECC's Deflection and Flexural Strength vs. SCMs Cement Replacement Rate}

Test results show that the increase of fly ash to cement ratio (FA/C) from 1.2 to 2.2 improved the deflection capacity of ECC mixtures (Table 4 and Figure 2). The improvement in the deflection capacity with the increase in the FA content can be attributed to the fact that the increase in the FA content tends to reduce the PVA fiber/matrix interface chemical bond and matrix toughness, while increasing the interface frictional bond, in favor of attaining high deflection capacity [12,18]. The slag-ECC mixes 
showed significantly lower deflection capacity when compared to that of the FA-ECC mixes. The reduced deflection capacity can possibly be caused by the higher fracture energy, bond strength and friction between the slag-ECC matrix and the fibers compared with FA-ECC mixes. Previous microstructural studies of slag-ECC mixtures showed that almost all slag-ECC particles participated in hydration process and no un-hydrated particles could be observed after the process of hydration [1]. This means that the fiber surfaces in slag-ECC have more attached matrix material compared to FA-ECC. For a fiber to be pulled out of the slag-ECC matrix, de-bonding at the fiber interface or fracture of the hydrate product is required to overcome interlocking of the hydrate product [1]. It should be noted that the flexural strength values of ECC mixtures incorporating class-CI FA were slightly higher than those of ECC mixtures which were produced with class-F FA while mid-span beam deflection values of the former were lower than the later.

No significant influence of the FA or slag replacement rate from 1.2 to $2.2(55 \%$ to $70 \%)$ on the flexural strength values especially at the ages of 28 days or later in the tested range. However, even at about $70 \%$ replacement of cement by FA or slag, the flexural strength of ECC at 28 days was significantly higher than that of conventional concrete and fiber reinforced concrete.

\subsection{ECC's Deflection and Flexural Strength vs. Aggregate Size}

Adverse effect of increased size of aggregates on deflection capacity performances of ECC mixtures was observed. The increase in aggregate size up to $1.18 \mathrm{~mm}$ slightly reduces the total mid-span beam deflection of ECC mixtures as shown in Table 4. This negative effect of increasing aggregate size may be attributed to the adverse effect on the uniform dispersion of fibers. The balling of fibers encouraged by coarser sands at constant sand content prevents sufficient coating of fibers by the matrix, and thus reduces the fiber-to-matrix bonding, which is an important factor influencing ductility [12]. Moreover, for ECC with the larger aggregate size, a higher degree of aggregate interlock is expected, resulting in higher matrix toughness and work-of-fracture during crack propagation. According to the micromechanical model of steady state cracking, which is essential to achieving strain hardening behavior, high matrix fracture toughness reduces the margin to develop multiple cracking [13]. However, aggregates within the size range studied, as long as they do not interfere with the uniform dispersion of fibers, do not negatively influence the ductility of ECC [12].

As in the case of cement replacement rate case, the aggregate particle size had no or only a minor effect on the flexural strength test results. Simultaneously, flexural strength and mid-span deflection obtained with crushed sand is within the permissible limit of silica sand and might be similar or even better than the mechanical properties of ECC mixtures made with silica sand [12].

It could be concluded that the most important feature of ECC, high deflection capacity with multiple cracking behaviors, was protected and is not sacrificed by replacing cement with a maximum of $70 \%$ FA or by replacing silica sand with local crushed sand.

\section{Analysis of General Fatigue Flexure Performance (Phase I)}

The first part of the Phase I aimed at investigating the flexural strength characteristics of the two ECC groups by applying static flexural testing at 28 and 56 days. The second part involved fatigue flexural tests which performed under load control conditions at 28 days where specimens were subjected to $4 \mathrm{~Hz}$ 
sinusoidal cyclic loading rate for 50,000 cycles at the fixed fatigue stress level of 55\% of the averaged flexural strength of ECC control specimens. At the end of the fatigue flexural tests, static flexural tests were applied on the fatigued ECC specimens to calculate the fatigue residual energy.

Table 5 shows the test results (for 12 ECC mixtures) of both static flexural testing without fatigue flexural loading and after fatigue flexural loading tests. By using these results, the percentage of fatigue residual energy of the fatigued ECC specimens for both residual stress and deflection could be calculated.

Table 5. Fatigue flexural test results (phase I).

\begin{tabular}{|c|c|c|c|c|c|c|c|c|}
\hline \multirow{2}{*}{$\begin{array}{l}\text { Mix } \\
\text { ID. }\end{array}$} & \multirow{2}{*}{$\begin{array}{c}\text { Mix } \\
\text { Designation }\end{array}$} & \multirow{2}{*}{$\begin{array}{l}\text { SCM/ } \\
\text { C (\%) }\end{array}$} & \multicolumn{2}{|c|}{ Static Flexural Testing } & \multicolumn{2}{|c|}{ Static Flexural after Fatigue Testing } & \multicolumn{2}{|c|}{ Residual Energy (\%) } \\
\hline & & & $\begin{array}{l}\text { Stress } \\
(\mathrm{MPa})\end{array}$ & $\begin{array}{c}\text { Deflection } \\
(\mathbf{m m})\end{array}$ & Stress (MPa) & Deflection (mm) & $\begin{array}{c}\text { Residual } \\
\text { Stress (\%) }\end{array}$ & $\begin{array}{c}\text { Residual } \\
\text { Deflection (\%) }\end{array}$ \\
\hline 1 & CI_1.2_SS & \multirow{4}{*}{$55 \%$} & 12.68 & 3.17 & 11.77 & 3.92 & 92.82 & 123.66 \\
\hline 3 & F_1.2_SS & & 11.80 & 3.91 & 11.16 & 5.29 & 94.58 & 135.29 \\
\hline 7 & CI_1.2_CS & & 12.20 & 2.86 & 10.72 & 3.32 & 87.87 & 116.08 \\
\hline 9 & F_1.2_CS & & 11.20 & 3.66 & 10.75 & 4.81 & 95.98 & 131.42 \\
\hline 2 & CI_2.2_SS & \multirow{4}{*}{$70 \%$} & 11.98 & 3.96 & 7.91 & 2.41 & 66.03 & 60.86 \\
\hline 4 & F_2.2_SS & & 10.84 & 4.45 & 7.04 & 3.09 & 64.94 & 69.44 \\
\hline 8 & CI_2.2_CS & & 11.42 & 3.14 & 8.13 & 2.58 & 71.19 & 82.13 \\
\hline 10 & F_2.2_CS & & 10.48 & 4.27 & 11.88 & 5.55 & 113.39 & 129.98 \\
\hline 5 & SL_1.2_SS & \multirow{2}{*}{$55 \%$} & 15.44 & 1.79 & 8.91 & 0.94 & 57.73 & 52.57 \\
\hline 11 & $\mathrm{SL} \_1.2 \_\mathrm{CS}$ & & 14.93 & 1.73 & 11.12 & 1.17 & 74.45 & 67.80 \\
\hline 6 & SL_2.2_SS & \multirow{2}{*}{$70 \%$} & 14.08 & 2.04 & 6.33 & 0.82 & 44.98 & 40.10 \\
\hline 12 & $\mathrm{SL} \_2.2 \_\mathrm{CS}$ & & 13.62 & 1.80 & 9.35 & 0.96 & 67.44 & 53.11 \\
\hline
\end{tabular}

As seen from Table 5, FA-ECC mixtures with 55\% cement replacement $(\mathrm{FA} / \mathrm{C}=1.2)$ showed superior performance relative to higher volume fly ash mixtures with $70 \%$ cement replacement $(\mathrm{FA} / \mathrm{C}=2.2)$ with respect to both fatigue flexural strength and deflection. The fatigue flexural strength remains equal or slightly lower than static flexural strength.

It was reported that conventional plain concrete with class-C fly ash mixture having $15 \%$ cement replacement showed superior performance relative to high-volume fly ash mixture with $50 \%$ cement replacement with respect to compressive strength and flexural fatigue strength [29]. Moreover, Tse et al. [30] indicated that concrete with equivalent or higher compressive and fatigue strength could be obtained with cement replacement of $25 \%$ by weight of low-calcium fly ash (class-F) or $50 \%$ by weight of high-calcium fly ash (class-C). The reason of ordinary performance of FA-ECC mixtures with 70\% cement replacement relative to $55 \%$ cement replacement in both fatigue flexural strength and deflection can be attributed to the fixation of fatigue stress level at 55\%. In addition, Suthiwarapirak et al. [28] indicated that the evolution of mid-span deflection depends on the fatigue stress level. Namely, the mid-span deflection increased to more than twice as much under high fatigue stress levels $S=0.8-0.9$ compared to that under low stress levels $S=0.5-0.6$. However, as shown in the Table 5, fly ash concrete mixtures with cement replacement $55 \%$ and $70 \%$ showed almost the same results when flexural fatigue strength was expressed as percentage of the flexural static strength.

Fatigue test results showed that F_2.2_CS ECC mixture with crushed sand had a remarkable performance with respect to both fatigue flexural strength and deflection capacity. The performance of 
F_2.2_CS ECC mixture was almost equal to that of all other FA-ECC mixtures with 55\% cement replacement in term residual deflection. The higher residual strength and deflection capacity F_2.2_CS ECC mixture compared to other ECC mixtures (as illustrated in Table 5) may be attributed to high water demand of class $\mathrm{F}$ fly ash (causing higher degree of hydration) leading to denser matrix and increased friction among crushed sand particles and PVA fivers.

Slag-ECC mixtures with 55\% and 70\% cement replacement exhibited inferior performance with respect to both flexural fatigue strength and deflection. It was found out that the compressive fatigue limit ratios at two million cycles in water were $41 \%$ for the concrete with blast furnace slag, $44 \%$ for the silica fume concrete, and $31 \%$ for the plain cement concrete at $50 \%$ probability of survival fatigue life [31]. Higher chemical bond strength between slag particles and fibers compared with FA-ECC results in significant lower deflection capacity and inferior performance in residual fatigue flexural strength and deflection capacity of slag-ECC mixtures. Although slag-ECC mixtures exhibit lower deformation capacity compared with FA-ECC, their flexural deflection capacity is around or more than $2 \mathrm{~mm}$ at 28 days of age. The $2 \mathrm{~mm}$ deflection capacity remains almost 150 times higher than that in normal concrete and conventional fiber reinforced concrete.

The $70 \%$ cement replacement group rather than 55\% was chosen for investigation in Phase II due to number of reasons. In general, fly ash has been used to replace cement in ECC mixture because of the absence of coarse aggregate in ECC results in higher cement content. Partial replacement using FA reduces the environmental burden. Further, it has been found that the addition of FA at high volumes improves the fresh and durability properties, reduces the drying shrinkage and matrix toughness, and improves the robustness of ECC in terms of tensile ductility [18,19]. Additionally, un-hydrated FA particles with a small particle size $(<45 \mu \mathrm{m})$ and smooth spherical shape serve as filler particles resulting in higher compactness of the fiber/matrix interface transition zone that leads to a higher frictional bond, which aids in reducing the steady-state crack width beneficial for the long-term durability of the structure [18,19].

Accordingly, fly ash-to-cement ratio (FA/C) of 2.2 was chosen in phase II to satisfy the above requirements. The ECC mixtures selected to be involved in the second phase were CI_2.2_SS, F_2.2_SS, CI_2.2_CS and F_2.2_CS.

\section{Analysis of Special Fatigue Flexure Performance (Phase II)}

In this phase, fatigue flexure tests were conducted on 28 day specimens in two different approaches; the first approach applied different fatigue flexural stress levels namely $40 \%, 55 \%$ and $70 \%$ of the average maximum static stress for 50,000 cycles at $4 \mathrm{~Hz}$ cyclic loading rate and the second approach applied different fatigue cycles namely 200,000 cycles, 300,000 cycles and 1,000,000 cycles at $4 \mathrm{~Hz}$ cyclic loading rate and 55\% fatigue stress level as well. 


\subsection{First Approach—Fatigue Stress Levels}

\subsubsection{Mid-Span Deflection Evolution}

The evolution of the average mid-span deflection as the number of cycles increased to 50,000 cycles for ECC specimens with different fatigue stress levels of $40 \%, 55 \%$ and $70 \%$ are plotted in Figure 3 . Only a typical result at each fatigue stress level is shown in the figure.
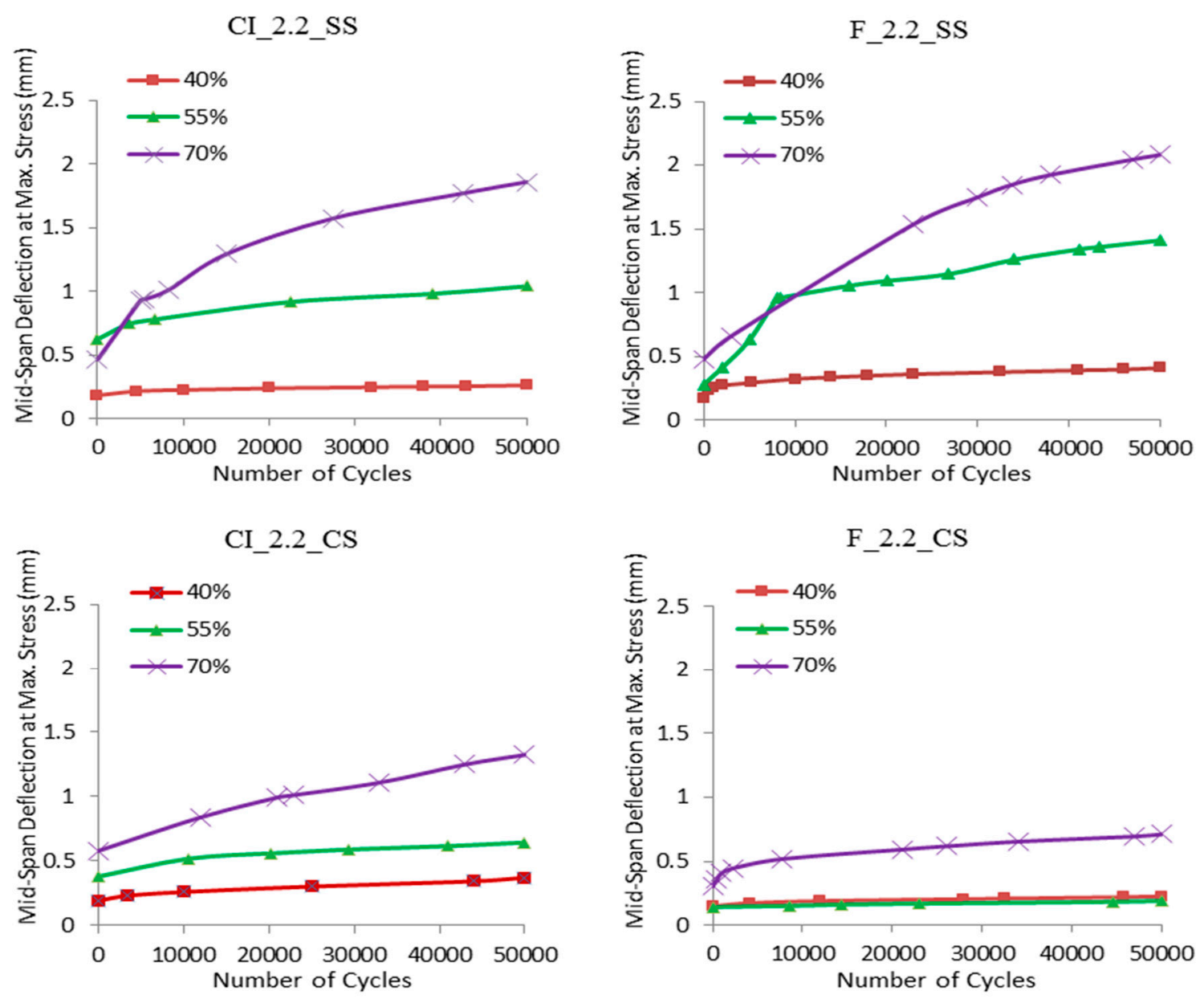

Figure 3. Evolution of mid-span deflection at different fatigue stress level (Phase I).

The results showed that FA-ECC specimens with silica sand (CI_2.2_SS and F_2.2_SS) under fatigue loading developed much more damage than FA-ECC specimens with crushed sand (CI_2.2_CS and F_2.2_CS). The range of displacement evolution of ECC specimens between the maximum stress and minimum stress levels was very large except for F_2.2_CS specimen. Under high stress level 70\%, the displacement at the maximum stress evolved up to about $2.1 \mathrm{~mm}$ mid-span deflection in silica sand ECC mixtures while the CI_2.2_CS specimen evolved up to $1.35 \mathrm{~mm}$ compared to $0.7 \mathrm{~mm}$ for the F_2.2_CS specimen. The evolution of the mid-span deflection was found to depend on the fatigue stress level. The mid-span deflection increased to around or more than twice at high fatigue stress level $70 \%$ compared to that under low fatigue stress level 55\%. It should be noted that FA-ECC mixtures with silica sand exhibited slightly higher deformation capacity than FA-ECC mixtures with crushed sand under static flexural loading while exhibited much higher deformation capacity under fatigue loading. 
It is also noticed that the CI_2.2_CS mixture exhibited higher deformation capacity than the F_2.2_CS mixture under fatigue loading. This is contrary to the fact that the former had lower deformation capacity than the latter under static flexural loading.

The fatigue flexural tests in this approach were applied for 50,000 cycles at $4 \mathrm{~Hz}$ cyclic loading rate. $4 \mathrm{~Hz}$ means 4 cycles per second; therefore, the time required to finish 50,000 cycles is $12,500 \mathrm{~s}$ or $208 \mathrm{~min}$. According to this, the mid-span evolution speed rate could be calculated at different fatigue stress levels, $40 \%, 55 \%$ and $70 \%$ of maximum static stress as shown in Table 6 . For example, as shown in Figure 3, at fatigue stress level 40\% for CI_2.2_SS mixture, the mid-span evolution started at $180 \mu \mathrm{m}$ and achieved at $260 \mu \mathrm{m}$ when the 50,000 cycles were done. The difference between these two values is $80 \mu \mathrm{m}$; divided this value by $208 \mathrm{~min}$ resulted in $0.39 \mu \mathrm{m} / \mathrm{min}$ as shown in Table 6 .

Table 6. Speed rate of mid-span deflection evolution at different fatigue stress levels.

\begin{tabular}{|c|c|c|c|c|c|c|c|}
\hline \multirow{4}{*}{$\begin{array}{l}\text { Mix } \\
\text { ID. }\end{array}$} & \multirow{4}{*}{$\begin{array}{c}\text { Mix } \\
\text { Designation }\end{array}$} & \multicolumn{6}{|c|}{ Fatigue Stress Levels } \\
\hline & & \multirow{2}{*}{\multicolumn{3}{|c|}{$\begin{array}{c}\text { Difference between First and } \\
\text { Last Values of Mid-Span Beam Deflection }(\mu \mathrm{m})\end{array}$}} & \multirow{2}{*}{\multicolumn{3}{|c|}{$\begin{array}{c}\text { Mid-Span Evolution } \\
\text { Speed Rate }(\mu \mathrm{m} / 208 \text { min })\end{array}$}} \\
\hline & & & & & & & \\
\hline & & $40 \%$ & $55 \%$ & $70 \%$ & $40 \%$ & $55 \%$ & $70 \%$ \\
\hline 1 & CI_2.2_SS & $260-180=80$ & $1040-630=410$ & $1860-465=1395$ & $80 / 208=0.39$ & 2.00 & 6.70 \\
\hline 2 & F_2.2_SS & $410-170=240$ & $1410-280=1130$ & $2080-480=1600$ & 1.15 & 5.43 & 7.70 \\
\hline 3 & CI_2.2_CS & $373-193=180$ & $645-381=264$ & $1325-580=745$ & 0.87 & 1.27 & 3.58 \\
\hline 4 & F_2.2_CS & $227-150=77$ & $192-143=47$ & $711-306=405$ & 0.37 & 0.24 & 1.95 \\
\hline
\end{tabular}

Figure 4 shows the speed rate of mid-span evolution for all ECC mixtures. As seen from the Figure and as was expected, FA-ECC mixtures with silica sand have the highest speed rate of the evolution of mid-span deflection than FA-ECC mixtures with crushed sand while F_2.2_CS has the lowest speed rate in the two groups. This means that silica sand mixtures are developing much more damage under fatigue loading. The results of speed rate mid-span evolution of all ECC mixtures are consistent with the results of mid-span deflection evolution (Figure 3).

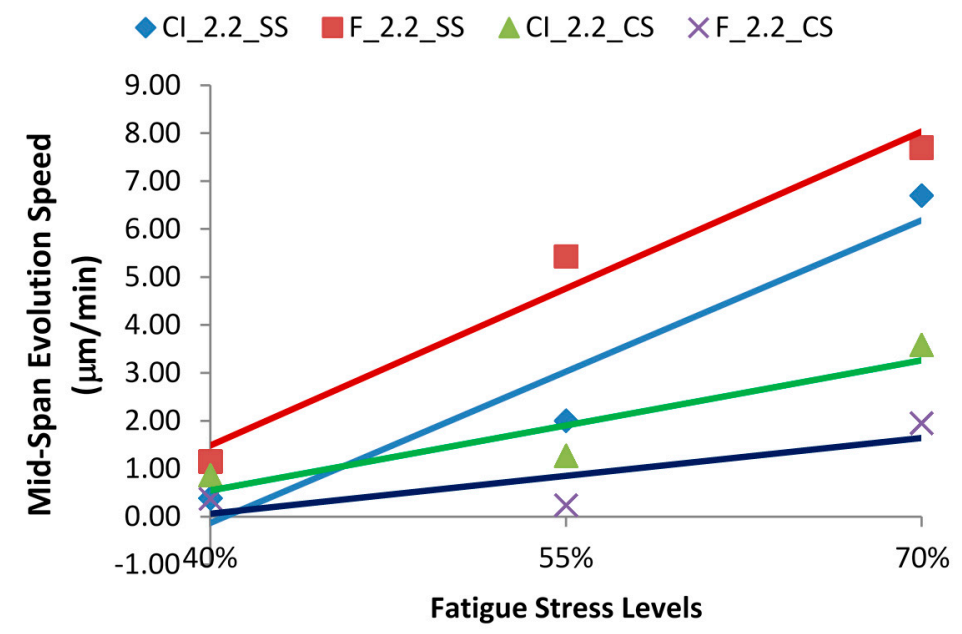

Figure 4. Speed rate of mid-span evolution at different fatigue stress levels. 


\subsubsection{Number and Width of Cracks}

Figures 5 and 6 illustrate the crack numbers and the crack widths of ECC mixtures respectively. It should be noted that the results in this section have been collected when the static flexural loading was applied after the fatigue flexural loading. The width of the crack was measured on the tension surface of the specimens by using a crack-scope.

It was found that more cracks formed at higher fatigue stress levels and unexpectedly few cracks formed at lower fatigue stress levels (Figure 5). At 40\% stress level, a small number of cracks formed, meaning that ECCs tend to behave in a similar fashion to single cracking conventional normal concrete. The reason behind this is not clear. Qian and $\mathrm{Li}$ [32] suggested that when the fatigue load level decreases, it is more difficult for ECC beams to reach saturated multiple cracking since the corresponding tensile stress at the bottom of the beam may be very close to the cracking strength. Based on general trend (Figure 5), the number of cracks should increase with the increase of fatigue stress level (generally associated more damage).

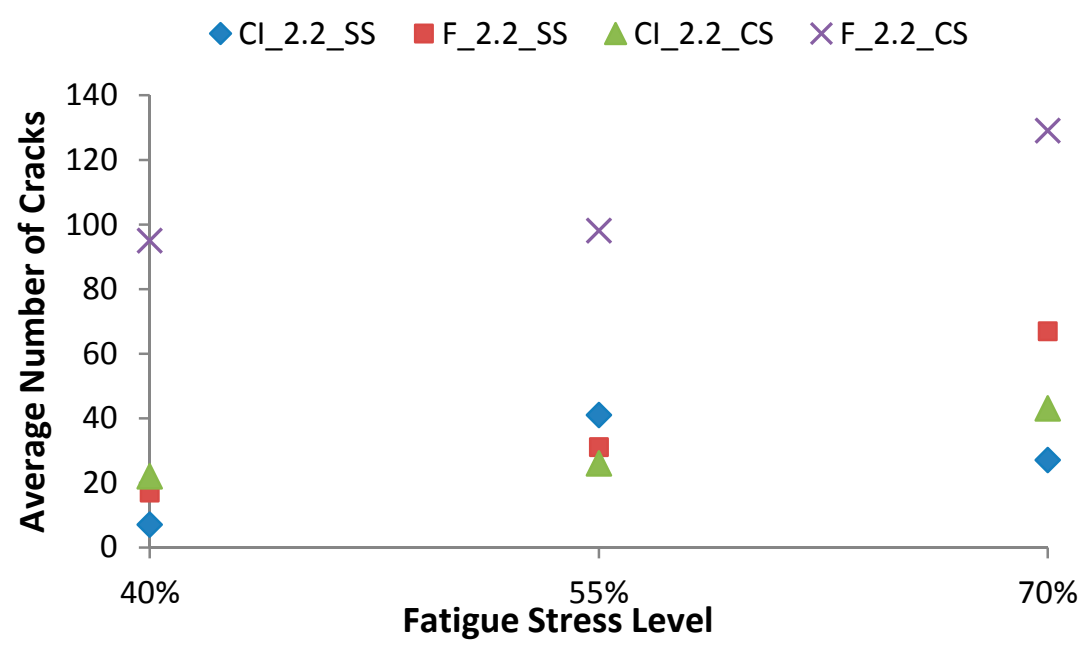

Figure 5. Average numbers of cracks at each fatigue stress level.

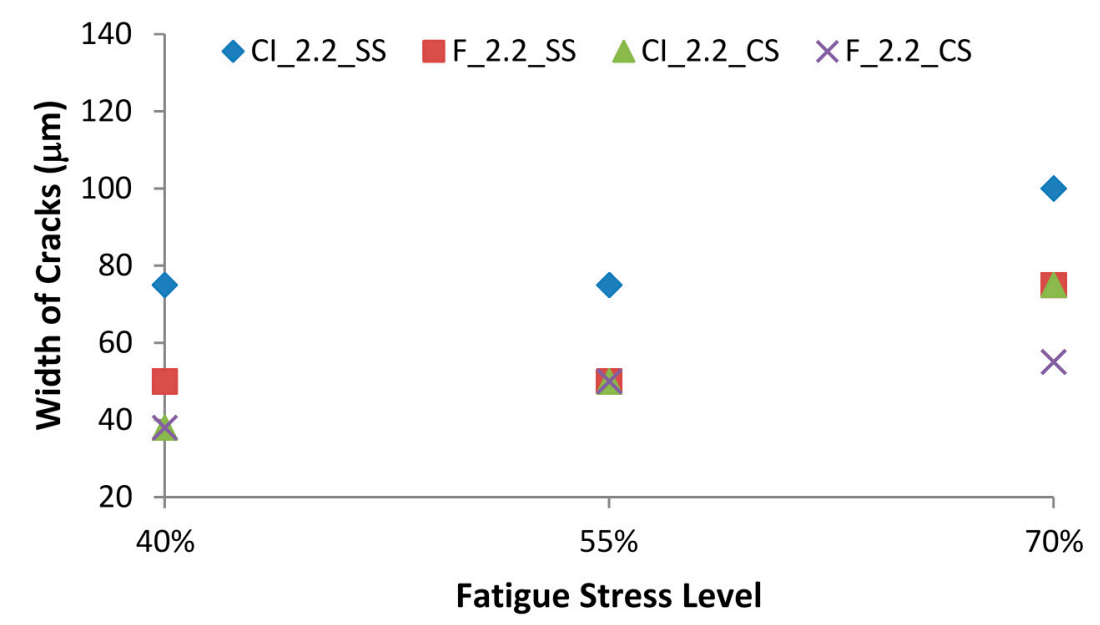

Figure 6. Crack Widths at each fatigue stress level. 
It was noticed that the F_2.2_CS mixture had higher number of cracks and smaller crack widths than other ECC mixtures as shown in Figures 5 and 6, respectively. However, it has to be mentioned again, at least at the range of low number of cycles studied in the present approach, that the large number of cracks with small width did not increase the deformation capacity in the case of fatigue as in F_2.2_CS mixture (Figure 3). As was expected, the relation between crack widths and fatigue stress level was directly proportional as shown in Figure 6.

In general, it can be concluded that the final number of multiple cracks of ECC mixtures is depending on a maximum fatigue stress level and also that the multiple-cracking behavior terminates earlier at a lower stress level.

It is essential to confirm whether or not multiple cracks can be formed in ECC mixtures even under fatigue loading, since structural applications can't be realized when the multiple cracking ability of ECC is negated during fatigue loading. Especially when improved durability is expected with ECC, the formation of fine multiple cracks is a necessary condition to minimize the migration of aggressive substances and could be the key to assess the feasibility of the structural applications under fatigue loading [33].

The results of the present study for fatigue testing confirmed that ECC mixtures showed multiple cracking under fatigue flexural loading as well as static flexural loading. Figure 7 confirms this fact. As shown in the photograph, the colored cracks resulted under fatigue flexural loading while the new, un colored, cracks resulted under static flexural loading which applied after fatigue loading to get the residual fatigue energy in the tested ECC beam. To highlight even more on the performance of F_2.2_CS and F_2.2_SS ECC mixtures according to multiple-cracking behavior, the results of both mid-span deflection evolution as in Figure 3 and crack measurement data as in both Figures 5 and 6 could be used. It can be concluded that the F_2.2_SS mixture exhibited more damage under fatigue loading than the F_2.2_CS ECC mixture as the evolutions of mid-span deflection was higher, and the total number of cracks of the SS mixture was lower than the CS mixture at the same fatigue stress level. This was caused by the fact that ECC exhibited multiple cracks and that the number of cracks initiated depended on the fatigue stress level. The number of cracks was higher when the specimens underwent high fatigue stress levels.

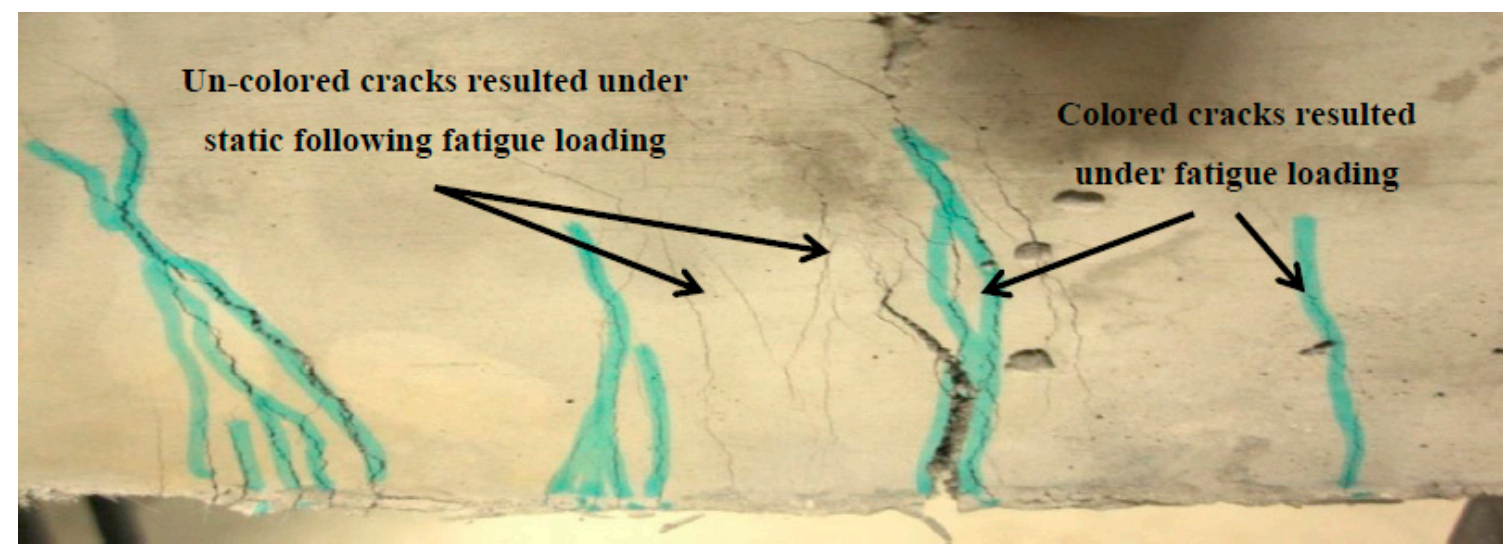

Figure 7. Multiple cracking under flexural fatigue loading.

\subsubsection{Static Tests Following Fatigue Loading}

At the end of the fatigue flexural tests as performed in the second part of the first phase, static flexural tests were applied on the exhausted and fatigued ECC specimens to calculate the fatigue residual energy 
for both strength and mid-span deflection. The fatigue flexural tests were expressed as percentages of static flexural tests and the residual strength and deflection are presented in Figures 8 and 9, respectively.

Figures 8 and 9 show that at higher fatigue stress level (70\%), all ECC mix designs exhibited higher strength and deformation capacity than lower fatigue stress levels (40\% and 55\%). It was indicated that when a high fatigue stress level was applied, ECCs exhibited a significantly prolonged fatigue life in comparison with other FRC due to their multiple crack characteristics. Their fatigue life tended to be equivalent to or become shorter than that of FRC at lower fatigue stress levels [28].

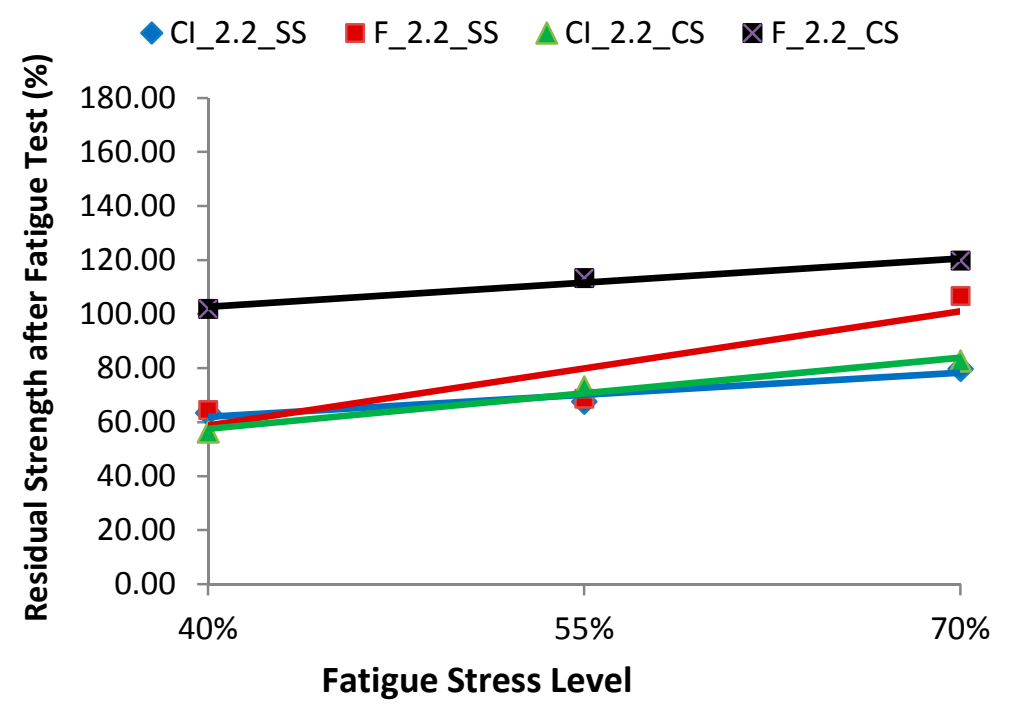

Figure 8. Percentages of residual strength after fatigue test.

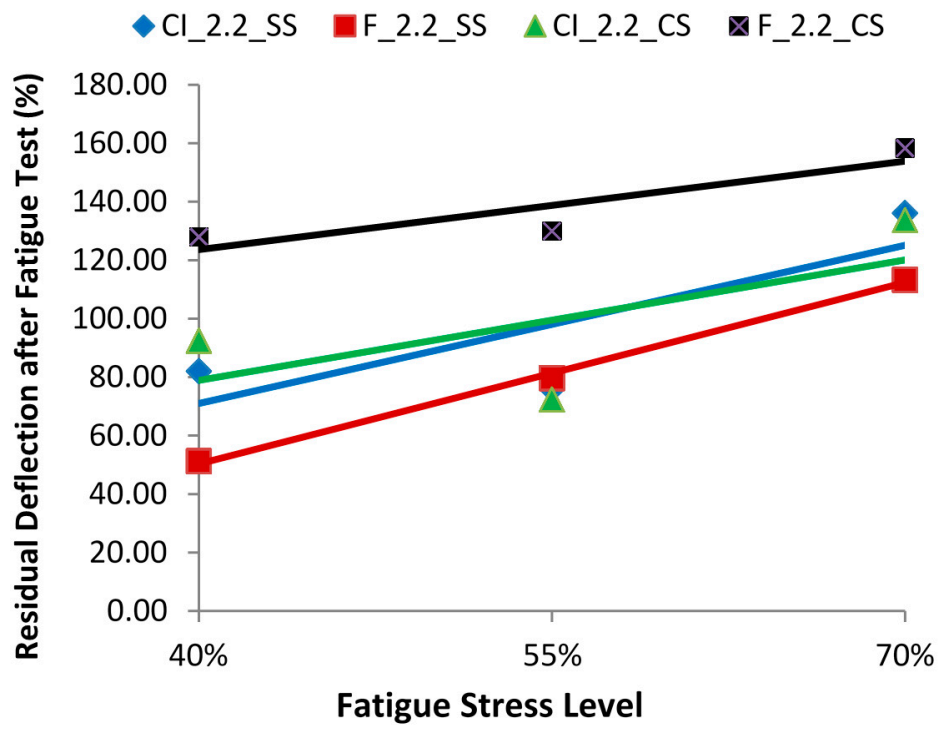

Figure 9. Percentages of residual mid-span deflection after fatigue test.

As mentioned in the first phase, at $55 \%$ of fatigue stress level, FA-ECC mixtures with $70 \%$ cement replacement exhibited ordinary performance relative to $55 \%$ cement replacement for both residual fatigue strength and deflection. It is found that when comparing ECC mixtures with $70 \%$ cement replacement under $70 \%$ of fatigue loading stress level to those $55 \%$ cement replacement under $55 \%$ of fatigue loading stress level, the former showed equal or slightly higher superior performance of the latter with respect 
to both residual fatigue strength and deflection. For convenience, the first phase results of both fatigue flexural strength and mid-span deflection are presented in Table 7 compared to present phase results. These results confirm that the selection for FA-ECC mixtures with $70 \%$ cement replacement to be included in the second phase was a good choice.

Table 7. Comparison between second and present Fatigue strength and deflection results.

\begin{tabular}{|c|c|c|c|c|c|}
\hline \multirow{2}{*}{$\begin{array}{l}\text { Mix } \\
\text { ID. }\end{array}$} & \multirow{2}{*}{$\begin{array}{c}\text { Mix } \\
\text { Designation }\end{array}$} & \multicolumn{2}{|c|}{$\begin{array}{c}\text { Residual Fatigue Energy at } \\
55 \% \text { of Stress Level (First Phase) }\end{array}$} & \multicolumn{2}{|c|}{$\begin{array}{c}\text { Residual Fatigue Energy at } \\
70 \% \text { of Stress Level (Present Phase) }\end{array}$} \\
\hline & & $\begin{array}{c}\text { Residual Stress } \\
\text { (\%) }\end{array}$ & $\begin{array}{c}\text { Residual Deflection } \\
\text { (\%) }\end{array}$ & $\begin{array}{c}\text { Residual Stress } \\
(\%)\end{array}$ & $\begin{array}{c}\text { Residual Deflection } \\
\text { (\%) }\end{array}$ \\
\hline 1 & CI_1.2_SS & 92.82 & 123.66 & - & - \\
\hline 3 & F_1.2_SS & 94.58 & 135.29 & - & - \\
\hline 7 & CI_1.2_CS & 87.87 & 116.08 & - & - \\
\hline 9 & F_1.2_CS & 95.98 & 131.42 & - & - \\
\hline 2 & CI_2.2_SS & 66.03 & 60.86 & 79.76 & 136.11 \\
\hline 4 & F_2.2_SS & 64.94 & 69.44 & 106.71 & 113.26 \\
\hline 8 & CI_2.2_CS & 71.19 & 82.13 & 82.69 & 133.69 \\
\hline 10 & F_2.2_CS & 113.39 & 129.98 & 119.76 & 158.29 \\
\hline
\end{tabular}

It is noticed that at $70 \%$ fatigue stress level, the F_2.2_SS mixture still shows high flexural strength capacity (106.71\%) even with larger deflections during fatigue loading found in the results of the mid-span deflection evolution $(2.082 \mathrm{~mm}$ ) (Figure 3). Again, it should be noted that the F_2.2_CS mixture shows the highest superior performance consistently at all fatigue stress levels with respect to residual fatigue flexural strength and mid-span deflection as shown in Figures 8 and 9, respectively. In the case of F_2.2_CS, it is noticed that the mid-span deflection evolution is inversely proportional to the residual fatigue flexural strength and mid-span deflection capacity. The lower the mid-span deflection evolution as in Figure 3 the higher the residual fatigue flexural strength and deflection capacity as in Figures 8 and 9, respectively. F_2.2_CS behaved as fiber reinforced concrete (FRC) under fatigue loading. Suthiwarapirak et al. [28] mentioned that the evolution of mid-span deflection for FRC was very small. But unlike FRC behavior when static loading was applied after fatigue loading at high fatigue stress levels, the residual energy for both stress and deflection was much larger than both FRC and F_2.2_SS in this study. To highlight the practical application of this finding; Li et al. [34] confirmed that the most important properties required for link slab applications are tensile strain capacity (ductility) and crack width control for durability purposes. The minimum ductility required to withstand temperature and drying shrinkage stress, as well as live loads, was computed to be $1.4 \%$ using a factor of safety of two. Furthermore, it was confirmed that crack widths should be below $100 \mu \mathrm{m}$ to minimize water/chloride penetration. These requirements are difficult, if not impossible, to attain for normal concrete, but are easily achievable with fly ash ECC mixtures with silica sand [34]. The current study revealed that the performance of fly ash ECC mixtures with crushed sand was comparable with that of silica sand mixtures under static loading while they exhibited much better performance under fatigue loading in terms of both residual fatigue flexural strength and deflection capacity. 


\subsection{Second Approach—Fatigue Number of Cycles}

The range of fatigue cycles studied in the first approach was somewhat low, only 50,000 cycles. Therefore, further fatigue experiments were needed to be applied with higher range of fatigue cycles to confirm the case of FA-ECC mixtures. In the second approach, the fatigue tests were applied at different fatigue cycles, namely 200,000 cycles, 300,000 cycles and 1,000,000 cycles. The specimens in the second approach were subjected to $4 \mathrm{~Hz}$ sinusoidal cyclic loading rate of $55 \%$ fatigue stress level.

\subsubsection{Mid-span Deflection Evolution}

The evolutions of mid-span deflection as function of the number of cycles are plotted in Figure 10 for each ECC specimens with 55\% fixed fatigue stress level.

At 1,000,000 cycles and as in fatigue stress level results (first approach), FA-ECC specimens with silica sand (CI_2.2_SS and F_2.2_SS) under fatigue loading developed much more damage than FA-ECC specimens with crushed sand (CI_2.2_CS and F_2.2_CS). The range of displacement evolution of FA-ECC specimens with silica sand was very large compared to FA-ECC specimens with crushed sand. Under stress level of $55 \%$, the displacement evolved up to about $1.10 \mathrm{~mm}$ mid-span deflection in silica sand ECC specimens compared to $0.53 \mathrm{~mm}$ crushed sand ECC specimens. The evolution of mid-span deflection was found to depend on the number of cycles in FA-ECC specimens with silica sand. The mid-span deflection increased to more than twice at high number of cycles $(1,000,000$ cycles $)$ compared to low number of cycles (200,000 and 300,000 cycles) as shown in Figure 10.
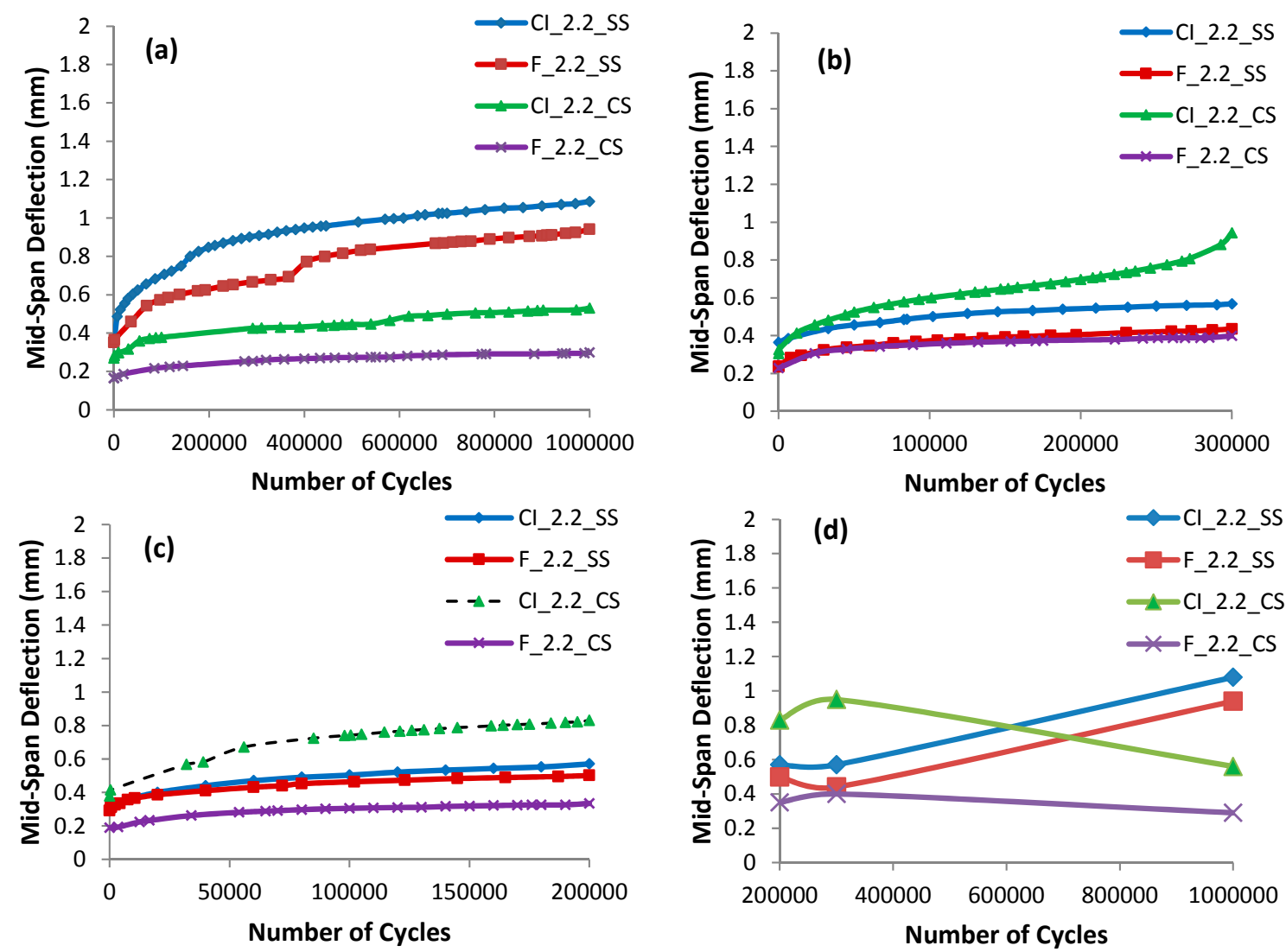

Figure 10. Evolution of mid-span deflection at 55\% fatigue stress level and different number of cycles: (a) 1,000,000 cycles; (b) 300,000 cycles; (c) 200,000 cycles; (d) Trends showing deflection evolutions. 
Un-expectedly, the relationship between the number of cycles and the evolution of mid-span deflection in FA-ECC specimens with crushed sand is inversely proportional. Their behavior for mid-span deflection evolution under high fatigue number of cycles was totally opposite to those with silica sand specimens. The more the number of cycles in FA-ECC with crushed sand the lower evolution of mid-span deflection, at least in the range of number of cycles studied in present study (Figure 10d). The reason behind this is not completely clear, but is likely associated with many un-hydrated spherical FA particles in the interfacial zone of FA-ECC mixtures which will make FA particles difficult to connect with other cement product crystals [1]. This is consistent with the fact that around $25 \%-30 \%$ in the paste with $50 \%$ replacement of fly ash did not hydrate and the unreacted fly ash may act like a micro-aggregate [35]. According to this, 70\% of cement replacement was used in the present study which means around $30 \%-40 \%$ of un-hydrated fly ash particles did not participate in the hydration process, but could be seen as mere filler material, or aggregate. Therefore, the use of crushed sand in FA-ECC mixtures facilitated to keep the un-hydrated fly ash particles as filler materials along with the PVA fibers due to its high porosity. FA-ECC mixtures with silica sand definitely reduced the chances for fly ash particles to act as a filler material because silica sand has extremely fineness than fly ash particles. Accordingly, when the fatigue tests applied on the crushed sand samples, the friction between cement crystals and the un-hydrated fly ash particles along with the confined PVA fibers in the zones of un-hydrated fly ash particles would be increased due to the fatigue vibration and bouncing. Thus, enhanced friction may increase the chance to reactivate and accelerate the chemical reaction between the three mentioned above parties. Further experimental works are needed to confirm the case of FA-ECC with crushed sand.

Furthermore, Song [1] indicated that the major phases of fly ash used in his study were glass phases containing mainly a $\mathrm{SiO}_{2}$ with $60 \%$ content. The FA glassy phase and the spherical particle shape may slow down the hydration process. This could indicate that FA-ECC mixture may have many un-hydrated particles featured with smooth surfaces, resulting in significant interface between the matrix and the FA particles. In the present study, $\mathrm{SiO}_{2}$ proportion was around $60 \%$ and $40 \%$ of fly ash class $\mathrm{F}$ and $\mathrm{CI}$ respectively. This shows that class $\mathrm{F}$ fly ash mixture has more un-hydrated fly ash particles than class CI mixture which may enhance the composite performance under fatigue loading as mentioned above.

According to the fact that the un-hydrated fly ash particles do not participate in the hydration process and $\mathrm{SiO}_{2}$ content, F_2.2_CS mixture exhibited better performance than CI_2.2_CS mixture. This is signified in Figure 10a-c, respectively. Figure 10 shows that the mid-span deflection evolution of F_2.2_CS was consistently less than CI_2.2_CS mixture at fatigue cycles of 200,000 cycles, 300,000 cycles and 1,000,000 cycles, respectively. Moreover, Figure 10d shows that the trend curve of F_2.2_CS mixture was more flat than CI_2.2_CS. This means that class-F fly ash mixture has a material characteristic independent of the number of cycles than all ECC mixtures mentioned herein at least within the range of fatigue number of cycles studied.

\subsubsection{Number and Width of Cracks}

To investigate the effect of fatigue loading on FA-ECC specimens, different fatigue number of cycles was applied on them namely 200,000 cycles, 300,000 cycles and 1,000,000 cycles. It should be noticed that the fatigue stress level was maintained at $55 \%$ for all of them. Again, it has to be mentioned that the 
results in this section had been collected when the static loading was applied following the fatigue loading. Crack numbers and widths of FA-ECC specimens are presented in Figures 11 and 12, respectively.

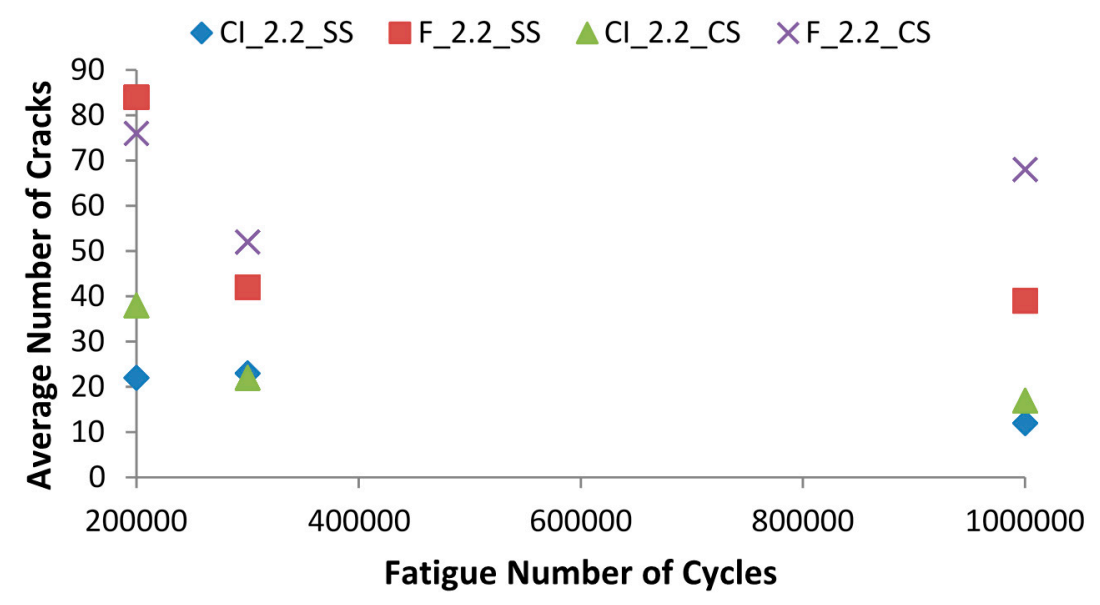

Figure 11. Average numbers of cracks at each fatigue number of cycles.

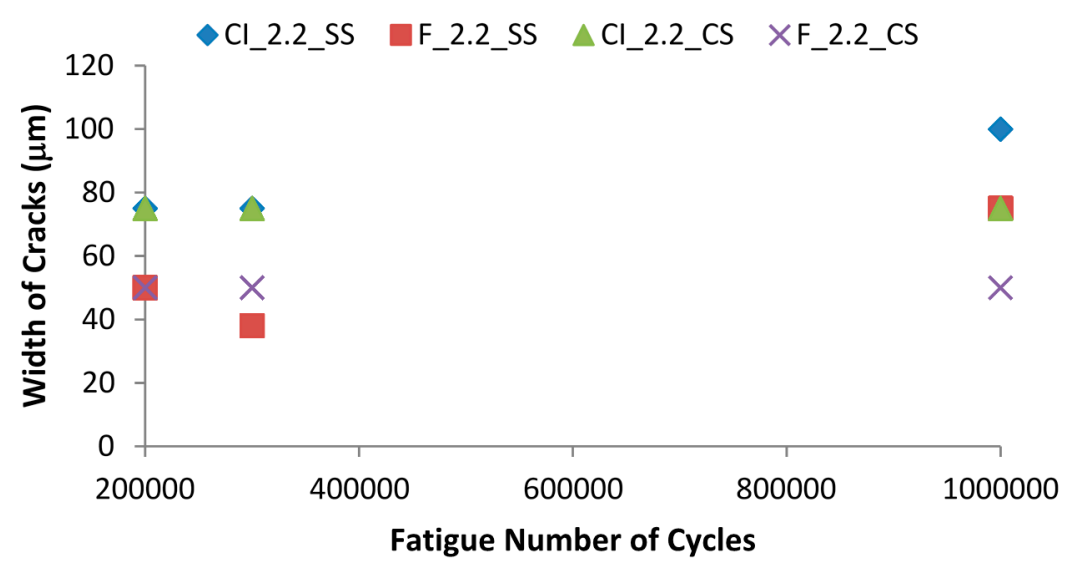

Figure 12. Crack widths at each fatigue number of cycles.

It was found that more cracks formed at lower fatigue number of cycles in FA-ECC mixtures and unexpectedly, few cracks were formed at higher fatigue number of cycles. This might be attributed to the fact that the fiber/matrix interfacial bond stress degradation results in fiber pullout and fiber fatigue results in fiber rupture [36]. Furthermore, Suthiwarapirak et al. [28] indicated that when comparing the fatigue specimens and static specimens, it was found that PVA fibers were severely ruptured under fatigue loading.

As in fatigue stress level results, first approach, F_2.2_CS mixture had higher number of cracks and smaller value of crack widths than other ECC mixtures as shown in Figures 11 and 12, respectively. It should be noted that F_2.2_CS and CI_2.2_CS mixtures exhibited the same value of crack width at all fatigue number of cycle tests, $50 \mu \mathrm{m}$ and $75 \mu \mathrm{m}$, respectively.

Although the final number of multiple cracks of FA-ECC mixtures was inversely proportional to the number of cycles, FA-ECC mixtures still showed multiple cracking under fatigue flexural loading as well as static flexural loading as shown in Figure 13. The photograph shows that the colored cracks resulted under fatigue flexural loading while the new, un-colored, cracks resulted under static flexural loading which applied after fatigue loading to get the residual energy in the tested ECC beam. 


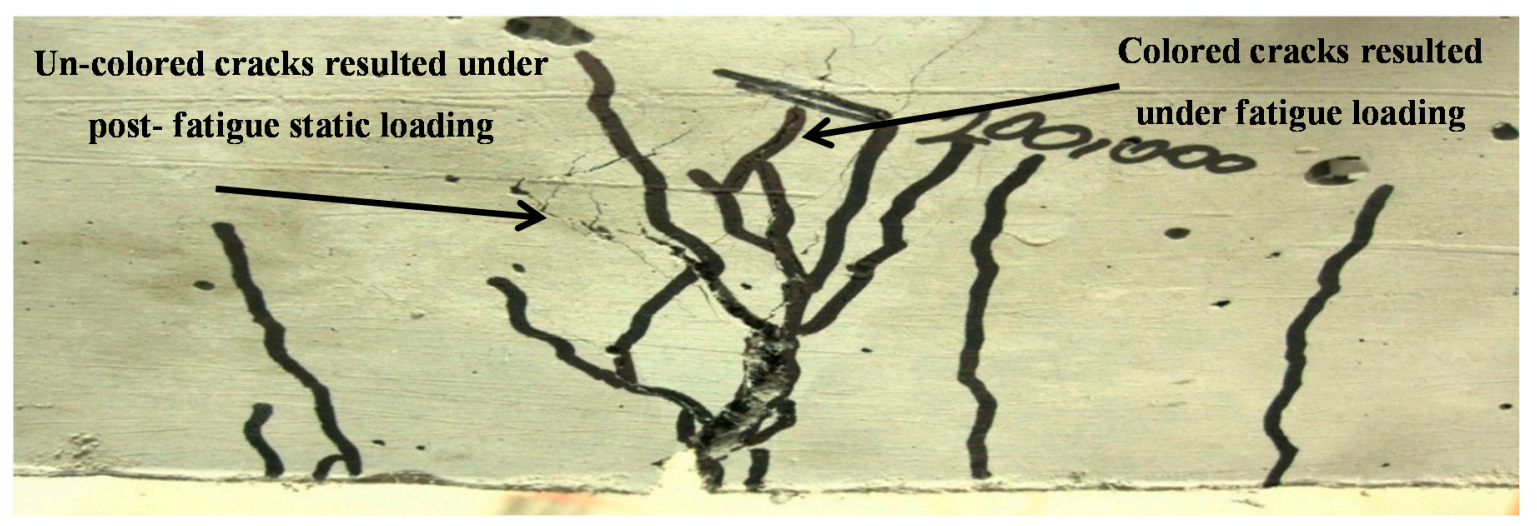

Figure 13. Multiple cracking under flexural fatigue loading.

\subsubsection{Static Loading Following Fatigue Loading}

Static flexural tests were applied on the fatigued ECC specimens to calculate the fatigue residual energy in terms of strength and mid-span deflection at the end of the fatigue flexural tests. The fatigue flexural tests were expressed as percentages of static flexural tests (in terms of residual strength and deflection) and are presented in Figures 14 and 15, respectively.

Figures 14 and 15 show that at higher number of cycles, FA-ECC mixtures with crushed sand exhibited higher residual energy in terms of flexural strength capacity than ECC mixtures with silica sand, while all ECC mixtures exhibited lower residual energy in terms of deflection capacity. These results are consistent with the mid-span deflection evolution results (Figure 10). It is found that the relation between the residual strength and the mid-span deflection evolution is inversely proportional. The lower the midspan deflection evolution, the higher the residual fatigue flexural strength and vice versa. As in fatigue stress level results, F_2.2_CS mixture shows the highest performance consistently for all number of cycles with respect to fatigue stress and mid-span deflection as shown in Figures 14 and 15, respectively.

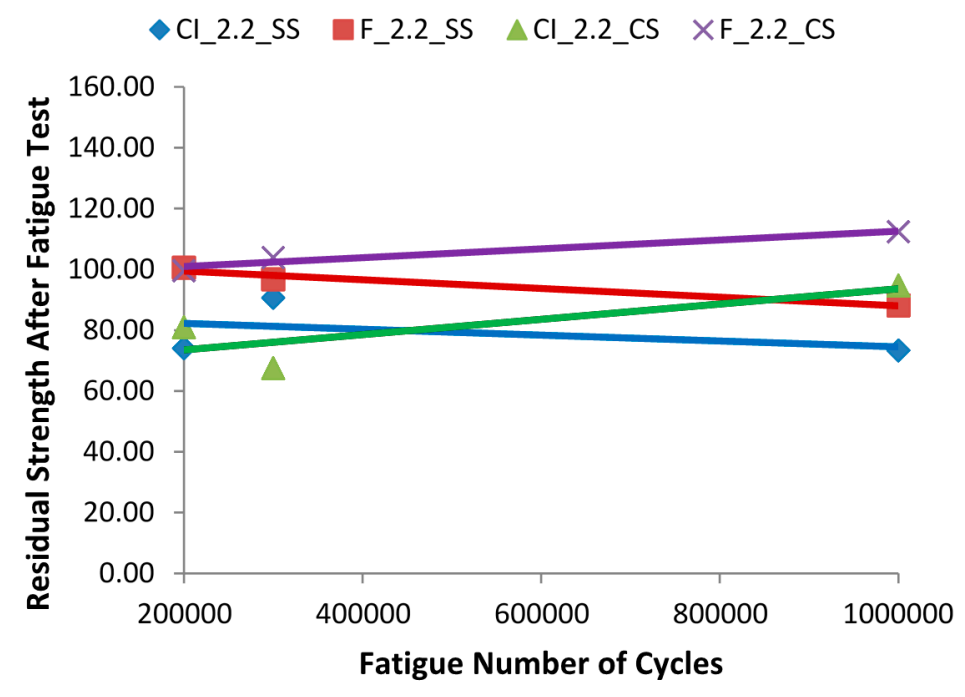

Figure 14. Percentages of residual strength after fatigue test. 


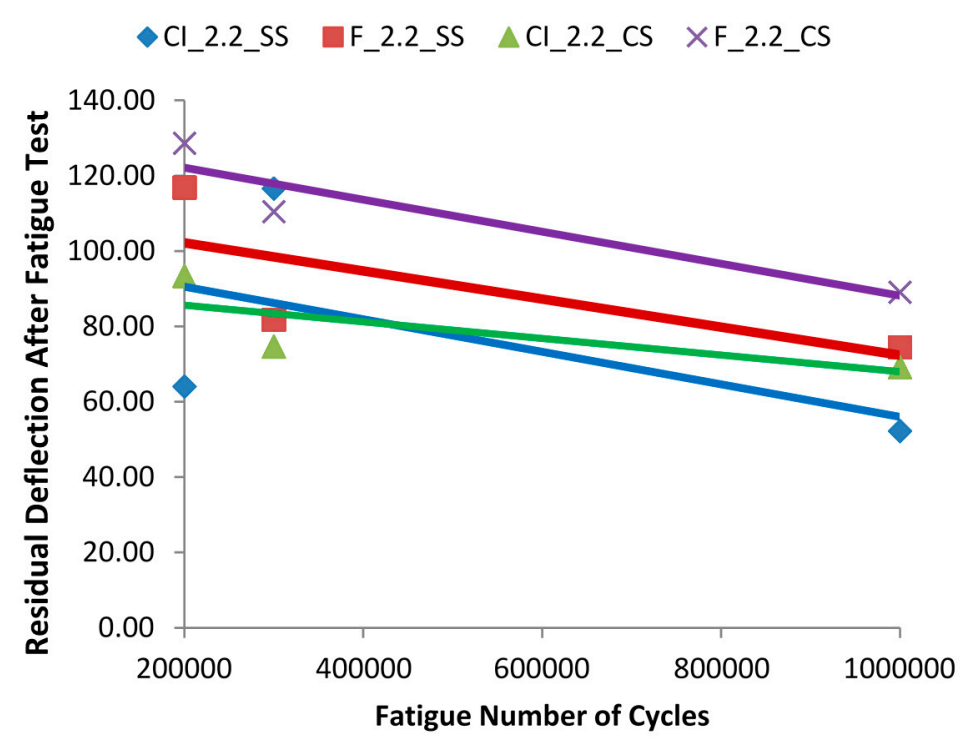

Figure 15. Percentages of residual mid-span deflection after fatigue test.

The good performance in residual energy of crushed sand ECC mixtures even after applied $1,000,000$ cycles could be attributed to the decrease in the maximum fatigue stress level. The stress level used herein was somewhat low, 55\%. According to this, Awad [37] reported that when normal concrete is subjected to high repeated stresses, a decrease of maximum stress level results in an increase of the number of cycles to failure. In addition to the decrease in fatigue stress level, high volume fly ash concrete subjected to high fatigue number of cycles at lower fatigue stress level as well would improve the performance of concrete. It was indicated that concrete with equivalent or higher compressive and fatigue strength of cylindrical concrete specimens incorporating large quantities of fly ash could be obtained with cement replacement of $25 \%$ by weight of low-calcium fly ash (class F) or $50 \%$ by weight of high-calcium fly ash (class C) [30]. Furthermore, Ramakrishnan et al. [38] revealed that the high-volume fly ash concrete has slightly higher (7\%) endurance limit when expressed as a ratio (ratio of flexural fatigue strength to static flexural strength) compared to plain Portland cement concrete. The results further indicated that there was an increase (15\% to 30\%) in static flexural strength for high-volume fly ash concrete which was previously subjected to four million cycles of fatigue stresses at their respective lower fatigue limit load (10\%). In the present study, both the decrease in fatigue stress level, which was 55\%, and the production of fly ash ECC mixtures with $70 \%$ cement replacement, could be the reasons for the superior performance in residual fatigue energy of crushed sand ECC mixtures. In addition to these two reasons, most researchers supported that during cyclic loading, fatigue of concrete occurs because of the propagation of the micro cracks and macro cracks present in the material, especially in the interface region as well as in the matrix. As an attempt to delay fatigue failure, Naik et al. [29] reported the addition of fiber to concrete restrict crack formation and delays crack growth. Therefore, unstable cracks produced during loading are transformed into a slow and controlled growth. The overall tensile rupture strain of concrete is increased due to the introduction of fiber which will lead to the great improvement in the fatigue life of concrete. 


\subsubsection{Fatigue Stress Life Diagram, $S-N$ Curve}

The fatigue stress $(S)$ to fatigue life versus the number of cycles $(N)$ relationships for FA-ECC mixtures are plotted on a semi-logarithmic scale as shown in Figure 16. All 28 days specimens reached one million cycles without failure.

Figure 16 shows all average static and fatigue test results of all ECC mixtures. The fatigue number of cycle's axis was drawn by the logarithmic scale to the base 10 while stress axis was drawn in normal scale. It should be noted that further fatigue experiments were done for all ECC mixtures types at 50,000 and 100,000 fatigue cycles in addition to 200,000,300,000 and 1,000,000 fatigue cycles to construct sufficient $S-N$ curve for all fly ash ECC mixtures. In this series of tests, two specimens at each static and fatigue loading were conducted. As shown in Figure 16, it is found that F_2.2_CS and F_2.2_SS mixtures exhibited prolonged fatigue life compared with other CI-ECC mixtures at higher fatigue number of cycles.

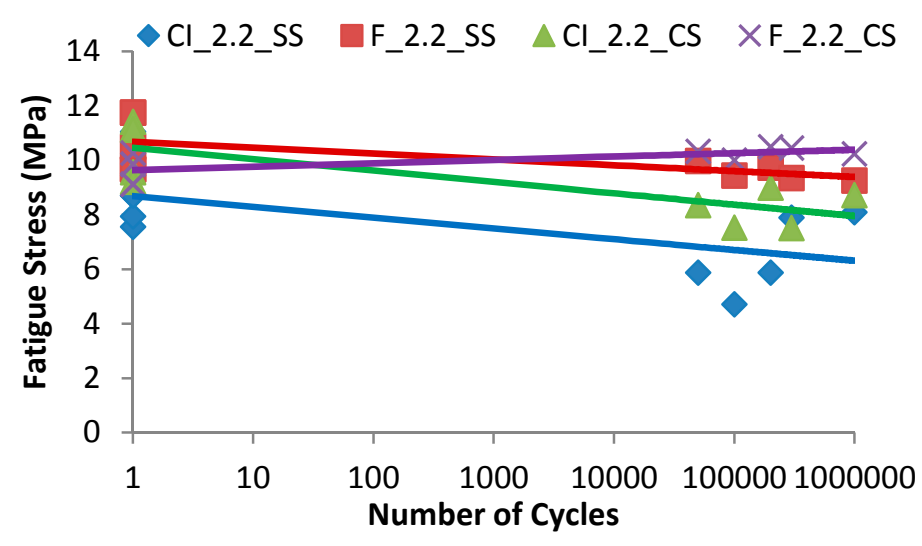

Figure 16. Fatigue stress-life relationships.

The flexural fatigue stress-life relationships of the four ECC mixtures can be expressed as a function of the fatigue stress, $S$, and logarithmic values of the number of cycles, $N$. The developed equations are:

CI_2.2_SS:

$$
S=-0.172 \ln (N)+8.6844, R^{2}=0.38
$$

F_2.2_SS:

$$
S=-0.093 \ln (N)+10.674, R^{2}=0.42
$$

CI_2.2_CS:

$$
S=-0.181 \ln (N)+10.456, R^{2}=0.65
$$

F_2.2_CS:

$$
S=0.054 \ln (N)+9.6397, R^{2}=0.48
$$

Unfortunately, on the $S-N$ curve for ECC mixtures, the author could not determine whether ECC mixtures exhibit a bilinear relation on a semi-logarithmic scale or not when compared to $S-N$ curve presented done by Suthiwarapirak et al. [28], which is similar to the $S-N$ relation of a metallic material. This is due to comparatively small number of fatigue cycles applied; one million cycles, compared to 
two million cycles by Suthiwarapirak et al. [28]. The authors could not have done more than one million cycles due to research time constraints.

In general, all ECC specimens showed superior fatigue strength compared to fatigue tests done by Zhang and Stang [39]. Table 8 shows fatigue strength results as a percentage of ultimate static flexural strength of the present study along with Zhang and Stang's results [39]. Fatigue flexural strength of plain concrete is $60 \%$, and that of fiber reinforced concretes (FRCs) varies from $65 \%$ for hooked end ( $2 \%$ fiber content) to $90 \%$ for smooth steel (1\%). Fatigue strength of polypropylene ECC (PE-ECC) is weaker than smooth steel (1\%), but stronger than hooked end (2\%). The fatigue strength of PE-ECC reaches as high as $78 \%$ of the ultimate static strength and it fails within the observed range of fatigue strength of FRCs [39]. FA-ECC mixtures with silica and crushed sand showed better fatigue strength performance at 1,000,000 cycle than all plain, FRCs and PE-ECC mixture except CI_2.2_SS mixture, which showed lower fatigue strength than FRCs but still a way better than plain concrete performance.

Table 8. Comparison between fatigue strength of plain concrete, fiber reinforced concretes (FRCs) [39], polypropylene engineered cementitious composites (PE-ECC) [33] and present study fly ash (FA)-ECC specimens.

\begin{tabular}{cccc}
\hline Concrete Type & $\begin{array}{c}\text { Ultimate Static } \\
\text { Strength (MPa) }\end{array}$ & $\begin{array}{c}\text { Fatigue Strength } \\
\text { (MPa) }\end{array}$ & $\begin{array}{c}\text { Fatigue Strength (\%) of Ultimate } \\
\text { Static Strength at 1 Million Cycles }\end{array}$ \\
\hline \multicolumn{4}{c}{ Plain Concrete and FRCS [39], and PE-ECC [33] } \\
\hline plain concrete & 6.94 & - & $60 \%$ \\
smooth steel 1\% & 10.15 & - & $90 \%$ \\
hooked steel 1\% & 9.88 & - & $87 \%$ \\
hooked steel 2\% & 12.82 & - & $65 \%$ \\
hooked steel 1\%+ & 9.46 & - & $87 \%$ \\
polypropylene 1\% & 8.12 & - & $78 \%$ failed at 0.88 million \\
PE-ECC 1.5\% & \multicolumn{2}{c}{ Present study fatigue strength } \\
\hline CI_2.2_SS & 11.04 & 8.095 & $73.32 \%$ \\
F_2.2_SS & 10.50 & 9.26 & $88.19 \%$ \\
CI_2.2_CS & 9.20 & 8.712 & $94.70 \%$ \\
F_2.2_CS & 9.11 & 10.24 & $112.40 \%$ \\
\hline
\end{tabular}

\subsubsection{The Case of F_2.2_CS ECC Mixture}

As a conclusion to the high performance of ECC mixture incorporating class-F fly ash with crushed sand, the mixture, F_2.2_CS, exhibited a unique performance which was equal to the superior performance of FA-ECC mixtures with 55\% cement replacement in fatigue deflection and even better than them in fatigue strength. For 50,000 cycles and 70\% higher fatigue stress level, the displacement evolution of F_2.2_CS mixture evolved up to $0.70 \mathrm{~mm}$ which was the lowest range of all other ECC mixtures. Accordingly, the speed rate of the mixture was $1.95 \mu \mathrm{m} / \mathrm{min}$ which is again the lowest fatigue speed rate. Higher number of cracks and lower crack widths of F_2.2_CS mixture at higher fatigue stress level, 70\%, was remarkable. Test results showed that F_2.2_CS mixture exhibited 120 numbers of crack and $50 \mu \mathrm{m}$ crack widths. The maximum numbers of crack and crack widths of all other ECC mixtures were 70 numbers of crack and $75 \mu \mathrm{m}$ crack width, respectively. 
At high fatigue number of cycles (1,000,000 cycles), F_2.2_CS mixture exhibited $0.30 \mathrm{~mm}$ displacement evolution range which was again the lowest value of all ECC mixtures. The average number of cracks of F_2.2_CS mixture at 1,000,000 cycles and at 55\% stress level was around 70 whereas the crack width was $50 \mu \mathrm{m}$ which was consistently remained fixed for all fatigue number of cycles (started at 200,000 through 1,000,000 cycles). It can be said that the F_2.2_CS mixture has material characteristics independent of the fatigue number of cycles of all FA-ECC mixtures, which means that the more this material is subjected to fatigue loading the more it gets stronger and more flexible at the same time, at least within the range of number of cycles studied.

Suthiwarapirak et al. [28] and Matsumoto et al. [40] reported that the age of specimens at fatigue flexural testing should be at least two months to alleviate the effect of initial hydration development. According to this, and due to the consistent superior performance in the case of F_2.2_CS mixture, the author preferred to conduct another flexural fatigue test for 1,000,000 cycles to the mentioned mixture at the age of 56 days to confirm this superiority. The mixture's specimen was subjected to similar fatigue loading conditions employed in the present study. It was subjected to $4 \mathrm{~Hz}$ sinusoidal cyclic loading rate at $55 \%$ fatigue stress level of the maximum static test result.

For comparison purposes, the evolution of mid-span deflection of this mixture was compared with all ECC mixtures mid-span deflection evolution. It can be found that the displacement evolved up to $0.6 \mathrm{~mm}$ mid-span deflection in F_2.2_CS_56 days compared to $0.3 \mathrm{~mm}$ in F_2.2_CS_28 days. The mid-span deflection increased to twice the value of 28 days mixture at high number of cycles $(1,000,000$ cycles $)$ as shown in Figure 17. The figure shows that mid-span deflection evolution of F_2.2_CS_56 days still exhibits less evolution than 28 days fly ash ECC mixtures with silica sand, even at the age of 56 days.

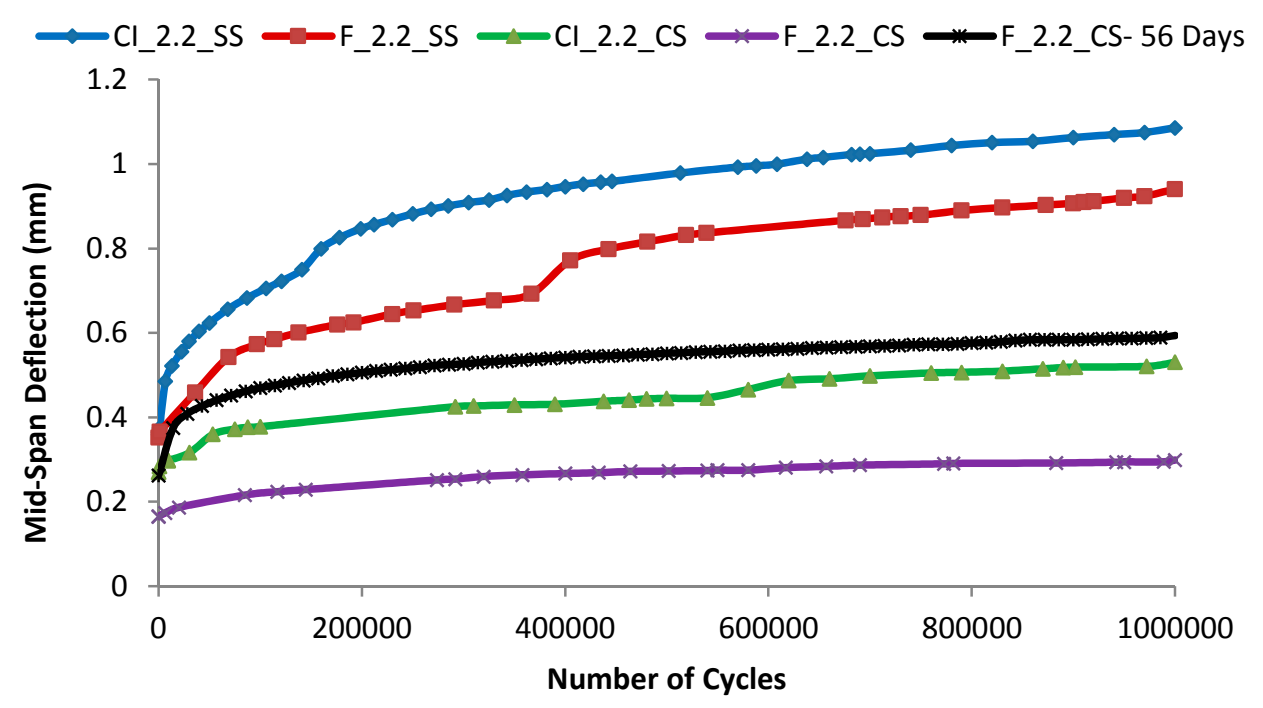

Figure 17. Evolution of mid-span deflection at 55\% fatigue stress level and 1,000,000 cycles.

Table 9 shows the fatigue loading characteristics of fly ash ECC mixtures studied in the second approach of fatigue performance including the characteristics of F_2.2_CS at the age of 56 days. The presented fatigue characteristics summarized in Table 9 are for fatigue flexural loading test results at one million cycles only. It should be mentioned again that the results in this section had been collected when static loading was applied after fatigue loading. Crack numbers, crack widths and residual fatigue 
energy expressed as percentages of static flexural tests (in terms of residual strength and deflection) of all FA-ECC mixtures mentioned above are presented in Table 9.

Table 9. Fatigue loading characteristics of fly ash ECC mixtures at one million cycles.

\begin{tabular}{|c|c|c|c|c|c|}
\hline \multirow{2}{*}{$\begin{array}{c}\text { Mix } \\
\text { Designation }\end{array}$} & \multirow{2}{*}{$\begin{array}{c}\text { Age of } \\
\text { Specimen }\end{array}$} & \multicolumn{2}{|c|}{ Static after Fatigue Loading } & \multicolumn{2}{|c|}{$\begin{array}{c}\text { Residual Fatigue Energy } \\
\text { at } 55 \% \text { Fatigue Stress Level }\end{array}$} \\
\hline & & Crack Numbers & Crack Width $(\mu \mathrm{m})$ & Residual Stress (\%) & Residual Deflection (\%) \\
\hline CI_2.2_SS & 28 & 12 & 100 & $73.32 \%$ & $52.22 \%$ \\
\hline F_2.2_SS & 28 & 39 & 75 & $88.19 \%$ & $74.46 \%$ \\
\hline CI_2.2_CS & 28 & 17 & 75 & $94.70 \%$ & $69.09 \%$ \\
\hline F_2.2_CS & 28 & 68 & 50 & $112.40 \%$ & $89.09 \%$ \\
\hline F 2.2 CS & 56 & 45 & 50 & $99.22 \%$ & $81.20 \%$ \\
\hline
\end{tabular}

As shown in Table 9, the F_2.2_CS mixture at 56 days still has higher number of cracks and smaller value of crack widths than fly ash ECC mixtures with silica sand and CI_2.2_CS mixture. It should be noted that both F_2.2_CS at 28 and 56 days exhibited the same value of crack width at 1,000,000 fatigue cycles test which was around $50 \mu \mathrm{m}$. Furthermore, Table 9 shows that F_2.2_CS mixture at 56 days exhibited better performance at 1,000,000 fatigue number of cycles with respect to residual fatigue flexural strength and mid-span deflection of all fly ash ECC mixtures except for the F_2.2_CS mixture at 28 days.

\section{Conclusions}

This paper describes the performance engineered cementitious composites (ECCs) under static and fatigue loading conditions. The variable parameters are: type and size of aggregates, type of supplementary cementing materials (SCMs), SCM/cement ratio of 1.2 or 2.2 (55\% or $70 \%$ by mass), fatigue stress levels $(40 \%, 55 \%$ and $70 \%)$, number of fatigue cycles $(50,000$ to $1,000,000)$ and age (up to 56 days). Twelve ECC mixtures produced from different combinations of mineral admixtures (both class CI and F fly ash as well as slag) and sands (silica sand and local crushed with maximum grain sizes of $0.42 \mathrm{~mm}$ and $1.18 \mathrm{~mm}$, respectively) are used. The aggregate/binder ratio is fixed at 0.36 and water/binder ratio is kept in the range of 0.27 for both class CI and F fly ash (FA) and 0.30 for slag ECC mixtures. The non-fatigue, fatigue and post-fatigue performances of ECC mixtures are determined based on flexural strength/deflection capacity, evolution of deflection and crack formation with crack width characteristics. The following conclusions are drawn from the study.

- The use of coarser local crushed sand in place of finer silica sand does not affect the deflection capacity and flexural strength of ECC mixtures for a particular SCM as long as polyvinyl alcohol (PVA) fibers are distributed evenly during the mixing process. The combination of sands (either silica or crushed) with different SCMs can affect both flexural strength and deflection capacity. The use of high volumes (up to 70\%) of SCMs produced ECC mixtures with enhanced bending ductility. Class F-fly ash was the best choice when combined with crushed sand (compared to class CI-fly ash and slag) in order to enhance the ECC ductility. Test results revealed that slag-ECC mixtures had lower deflection capacity under static loading. However, the deflection capacity 
under static loading of slag-ECCs remained 150 times greater than normal and conventional fiber reinforced concrete although they showed slightly higher flexural strength than FA-ECC mixtures.

- Under low fatigue cycles $(50,000)$ at constant stress level of 55\%, low volume $(55 \%)$ FA (both $\mathrm{CI}$ and F) ECC mixtures with both silica and crushed sands produced higher residual fatigue strength and deflection capacity compared to those made with high volume FA (70\%). Only exception was high volume class F FA-ECC mixture with crushed sand which showed similar behavior compared to those made of lower volume FA with both silica and crushed sands. However, slag-ECC mixtures showed inferior performance in terms of lower residual flexural strength and deflection capacity under fatigue loading compared to those with class F and CI fly ash.

- In both cases of high fatigue stress level (70\%) and high fatigue cycles (1,000,000 cycles), high volume FA-ECC mixtures with silica sand developed more damage in deformation capacity, bigger crack width and lower number of cracks than high volume FA-ECC mixtures with crushed sand. Silica sand ECCs developed crack width in less than or equal to $100 \mu \mathrm{m}$ whereas in general crack width was found to be reduced with the crushed sand $(<50 \mu \mathrm{m})$. It is interesting to note that the use of crushed sand seemed to have increased the resistance of ECC mixtures against fatigue damage (especially at higher number of cycles) due to capacity enhancement in terms of generating more internal energy. At high fatigue cycles up to 100,000, crushed sand-ECC mixtures showed the best performance (even at high stress level of $70 \%$ and at higher age of 56 days) exhibiting higher residual strength and deflection capacity compared to other mixtures with all combinations of both types of fly ash and sands.

- Fatigue tests at higher stress level (70\%) produced more multiple cracks and bigger crack width in FA-ECC mixtures than those conducted at low stress level (40\%). In addition, more cracks were formed during lower fatigue number of cycles $(200,000)$ and during higher fatigue number of cycles (1,000,000 cycles), few cracks were developed.

- It is concluded that the most important feature of ECC, high deflection capacity with multiple cracking behaviors, was protected and is not sacrificed by replacing cement with a maximum of $70 \%$ FA or by replacing silica sand with local crushed sand.

- The results confirmed that the use of crushed sand not only provide cost effective ECC mixtures but also better mechanical properties in terms of enhanced ductility, fatigue resistance and post-fatigue mechanical characteristics. Such ECC mixtures have great potential to be used in the construction building and bridge structures. However, more investigations are needed to explore the effect of crushed sand on durability performance of ECC mixtures. Researches are in progress on the short and long term properties as well as structural performance of joint-free bridge decks with ECC link slabs.

\section{Acknowledgments}

The authors gratefully acknowledge the financial assistances of Ministry of Transportation of Ontario (MTO) Highway Infrastructure Innovations Funding Program and National Science and Engineering Research Council (NSERC), Canada. Supports from Lafarge Canada and St. Marys Cement in terms of materials are highly appreciated. Special thanks to Hanna Schell, David Rhead and Clifford Lam of MTO 
as well as Abdurrahman Lotfy (Lafarge, Canada) and Wafiq Taha (St. Marys Cement, Canada) — their supports are gratefully acknowledged.

\section{Author Contributions}

This work was carried out in collaboration among all three authors. Mohamed A.A. Sherir carried out experiments, data analyses and prepared the draft of the manuscript. Khandaker M.A. Hossain designed the study, supervised the research, involved in experimental data analyses and prepared the manuscript for submission. Mohamed Lachemi was involved in supervision of the research and preparation of the manuscript. All three authors proof-read and approved the paper.

\section{Conflicts of Interest}

The authors declare no conflict of interest.

\section{References}

1. Song, G. Matrix Manipulation to Study ECC Behaviour. Master's Thesis, University of Stellenbosch, Matieland, South Africa, 2005.

2. Li, V.C.; Kanda, T. Engineered cementitious composites for structural applications. ASCE J. Mater. Civ. Eng. 1998, 10, 66-69.

3. Li, V.C.; Wang, S.; Wu, C. Tensile strain-hardening behavior of polyvinyl alcohol engineered cementitious composite (PVA-ECC). ACI Mater. J. 2001, 98, 483-492.

4. Li, V.C. On engineered cementitious composites (ECC): A review of the material and its applications. J. Adv. Concr. Technol. 2003, 1, 215-230.

5. Lin, Z.; Li, V.C. Crack bridging in fiber reinforced cementitious composites with slip-hardening interfaces. J. Mech. Phys. Solids 1997, 45, 763-787.

6. Lin, Z.; Kanda, T.; Li, V.C. On interface property characterization and performance of fiber reinforced cementitious composites. Concr. Sci. Eng. 1999, 1, 173-184.

7. Kong, H.J.; Bike, S.G.; Li, V.C. Development of a self-consolidating engineered cementitious composite employing electrosteric dispersion/stabilization. Cem. Concr. Compos. 2003, 25, 301-309.

8. Kong, H.J.; Bike, S.G.; Li, V.C. Constitutive rheological control to develop a self-consolidating engineered cementitious composite reinforced with hydrophilic poly(vinyl alcohol) fibers. Cem. Concr. Compos. 2003, 25, 333-341.

9. Kim, Y.Y.; Kong, H.; Li, V.C. Design of engineered cementitious composite suitable for wet-mixture shotcreting. ACI Mater. J. 2003, 100, 511-518.

10. Lepech, M.D.; Li, V.C. Large scale processing of engineered cementitious composites. ACI Mater. J. 2008, 105, 358-366.

11. Yang, E.; Li, V.C. A Micromechanical Model for Fiber Cement Optimization and Component Tailoring. In Proceedings of the 10th International Inorganic-Bonded Fiber Composites Conference, San Paulo, Brazil, 15-18 November 2006; pp. 1-13. 
12. Sahmaran, M.; Lachemi, M.; Hossain, K.M.A.; Ranade, R.; Li, V.C. Influence of aggregate type and size on ductility and mechanical properties of engineered cementitious composites. $A C I$ Mater. J. 2009, 106, 308-316.

13. Li, V.C.; Mishra, D.K.; Wu, H.C. Matrix design for pseudo-strain-hardening fibre reinforced cementitious composites. Mater. Struct. 1995, 28, 586-595.

14. Fischer, G.; Wang, S.; Li, V.C. Design of engineered cementitious composites (ECC) for processing and workability requirements. In Brittle Matrix Composites 7; Brandt, A.M., Li, V.C., Marshall, M.H., Eds.; Woodhead Publishing: Cambridge, UK, 2003; pp. 29-36.

15. Mehta, P.K. Influence of fly ash characteristics on the strength of portland-fly ash mixtures. Cem. Concr. Res. 1985, 15, 669-674.

16. Kim, Y.Y.; Kim, J.S.; Kim, H.S.; Kim, J.K.; Ha, G.J. Uniaxial Tensile Behavior of High Ductile Fiber Reinforced Mortar Designed with Ground Granulated Blast Furnace Slag. In Proceedings of the KSCE Annual Conference, Pyung-Chang, Korea, 20-22 October 2004; pp. 546-551.

17. Kim, J.K.; Kim, J.S.; Ha, G.J.; Kim, Y.Y. Tensile and fiber dispersion performance of ECC (engineered cementitious composites) produced with ground granulated blast furnace slag. Cem. Concr. Res. 2007, 37, 1096-1105.

18. Wang, S.; Li, V.C. Engineered cementitious composites with high-volume fly ash. ACI Mater. J. 2007, 104, 233-241.

19. Yang, E.-H.; Yang, Y.; Li, V.C. Use of high volumes of fly ash to improve ECC mechanical properties and material greenness. ACI Mater. J. 2007, 104, 303-311.

20. Zhou, J.; Qian, S.; Sierra Beltran, M.G.; Ye, G.; Breugel, K.; Li, V.C. Development of engineered cementitious composites with limestone powder and blast furnace slag. Mater. Struct. 2010, 43, 803-814.

21. Lepech, M.; Li, V.C. Water Permeability of Cracked Cementitious Composites. In Proceedings of the 11th International Conference on Fracture (ICF11), Turin, Italy, 20-25 March 2005; p. 4539.

22. Lepech, M.; Li, V.C. Durability and long term performance of engineered cementitious composites (ECC). In International RILEM Workshop on High Performance Fiber Reinforced Cementitious Composites in Structural; Fischer, G., Li, V.C., Eds.; RILEM Publications SARL: Bagneux, France, 2006; pp. 165-174.

23. Caner, A.; Zia, P. Behavior and design of link slabs for jointless bridge decks. PCI J. 1998, 43, 68-80.

24. Hossain, K.M.A.; Lachemi, M.; Kayes, M.A.; Mavani, M.B. Influence of ECC Mixture on the Structural Performance of Link Slabs in Bridge Decks. In Proceedings of the 3rd Specialty Conference on Material Engineering \& Applied Mechanics, Montréal, Québec, Canada, 29 May-1 June 2013.

25. Li, V.C.; Wu, C.; Wang, S.; Ogawa, A.; Saito, T. Interface tailoring for strain-hardening polyvinyl alcohol-engineered cementitious composite (PVA-ECC). ACI Mater. J. 2002, 99, 463-472.

26. American Society for Testing and Materials. Standard Test Method for Slump Flow of Self-Consolidating Concrete; ASTM C1611 2014; American Society for Testing and Materials: West Conshohocken, PA, USA, 2014.

27. American Society for Testing and Materials. Standard Test Method for Flexural Strength of Concrete (Using Simple Beam with Third-Point Loading); ASTM C78 2002; American Society for Testing and Materials: West Conshohocken, PA, USA, 2002. 
28. Suthiwarapirak, P.; Matsumoto, T.; Kanda, T. Multiple cracking and fiber bridging characteristics of engineered cementitious composites under fatigue flexure. J. Mater. Civ. Eng. ASCE 2004, 16, 433-443.

29. Naik, T.; Singh, S.; Ye, C. Fatigue Behavior of Plain Concrete Made with or without Fly Fsh; The Department of Civil Engineering and Mechanics, University of Wisconsin-Milwaukee for Electric Power Research Institute (EPRI): Palo Alto, CA, USA, 1993.

30. Tse, E.W.; Lee, D.Y.; Klaiber, F.W. Fatigue Behavior of Concrete Containing Fly Ash. In Proceedings of the Second International Conference on the Use of Fly Ash, Silica Fume, Slag and Natural Pozzolans in Concrete, Madrid, Spain; Malhotra, V.M., Ed.; American Concrete Institute Special Publication: Madrid, Spain, 1986; pp. 273-290.

31. Ozaki, S.; Sugata, N. Fatigue of Concrete Composed of Blast Furnace Slag or Silica Fume under Submerged Conditions; Malhotra V.M., Ed.; American Concrete Institute (ACI): Detroit, MI, USA, 1992; pp. 1509-1524.

32. Qian, S.; Li, V.C. Durable pavement with ECC. In International Conference on Microstructure Related Durability of Cementitious Composites; Sun, W., van Breugel, K., Miao, C., Ye, G., Chen, H., Eds.; RILEM Publications: Bagneux, France, 2008; pp. 535-543.

33. Matsumoto, T. Fracture Mechanics Approach to Fatigue Life of Discontinuous Fiber Reinforced Composites. Ph.D. Thesis, Department of Civil and Environmental Engineering, University of Michigan, Ann Arbor, MI, USA, 1998.

34. Li, V.C.; Lepech, M.; Wang, S.; Weimann, M.; Keoleian, G. Development of green ECC for sustainable infrastructure systems. In Proceedings of the International Workshop on Sustainable Development and Concrete Technology, Beijing, China, 20-21 May 2004; pp. 181-192.

35. Termkhajornkit, P.; Nawa, T.; Nakai, M.; Saito, T. Effect of fly ash on autogenous shrinkage. Cem. Concr. Res. 2005, 35, 473-482.

36. Matsumoto, T.; Suthiwarapirak, P.; Asamoto, S. Model development of ECC fatigue analysis. Proc. Jpn. Concr. Inst. 2002, 24, 237-242.

37. Awad, M.E. Strength and Deformation Characteristics of Plain Concrete Subjected to High Repeated and Sustained Loads. Ph.D. Thesis, University of Illinois at Urbana, Champaign, IL, USA, 1971.

38. Ramakrishnan, V.; Malhotra, V.M.; Longley, W.S. Comparative evaluation of flexural fatigue behavior of high volume fly ash and plain concrete. ACI Spec. Publ. 2005, 229, 351-368.

39. Zhang, J.; Stang, H. Fatigue performance in flexure of fiber reinforced concrete. ACI Mater. J. 1998, 95, 58-67.

40. Matsumoto, T.; Suthiwarapirak, P.; Kanda, T. Mechanisms of multiple cracking and fracture of DFRCC under fatigue flexure. J. Adv. Concr. Technol. 2003, 1, 299-306.

(C) 2015 by the authors; licensee MDPI, Basel, Switzerland. This article is an open access article distributed under the terms and conditions of the Creative Commons Attribution license (http://creativecommons.org/licenses/by/4.0/). 